\title{
Dissecting the Role of Mesenchymal Stem Cells in Idiopathic Pulmonary Fibrosis: Cause or Solution
}

OPEN ACCESS

Edited by:

Anna Dmitriyevna Krasnodembskaya, Queen's University Belfast, United Kingdom

Reviewed by: Helen Parfrey,

Royal Papworth Hospital NHS Foundation Trust, United Kingdom Amiq Gazdhar,

Bern University Hospital, Switzerland Andreas Guenther,

University of Giessen, Germany

${ }^{*}$ Correspondence:

Massimo Dominici massimo.dominici@unimore.it

tThese authors share first authorship

FThese authors share senior authorship

Specialty section: This article was submitted to Respiratory Pharmacology, a section of the journal Frontiers in Pharmacology

Received: 08 April 2021 Accepted: 21 June 2021 Published: 05 July 2021

Citation:

Samarelli AV, Tonelli R, Heijink I,

Martin Medina A, Marchioni A,

Bruzzi G, Castaniere I, Andrisani D, Gozzi F, Manicardi L, Moretti A, Cerri S, Fantini R, Tabbì L, Nani C, Mastrolia I,

Weiss DJ, Dominici M and Clini E

(2021) Dissecting the Role of Mesenchymal Stem Cells in Idiopathic Pulmonary Fibrosis: Cause or Solution.

Front. Pharmacol. 12:692551. doi: 10.3389/fphar.2021.692551
Anna Valeria Samarelli, ${ }^{1,2 t}$, Roberto Tonelli ${ }^{1,2,3 t}$, Irene Heijink ${ }^{4}$, Aina Martin Medina ${ }^{5}$, Alessandro Marchioni ${ }^{1,2}$, Giulia Bruzzi ${ }^{1,2}$, Ivana Castaniere ${ }^{1,2,3}$, Dario Andrisani ${ }^{1,2,3}$, Filippo Gozzi ${ }^{1,2,3}$, Linda Manicardi ${ }^{1,2}$, Antonio Moretti ${ }^{1,2}$, Stefania Cerri ${ }^{1,2}$, Riccardo Fantini ${ }^{2}$, Luca Tabbi $^{2}$, Chiara Nani ${ }^{2}$, Ilenia Mastrolia ${ }^{6}$, Daniel J. Weiss ${ }^{7}$, Massimo Dominici ${ }^{8 * \neq}$ and Enrico Clini ${ }^{1,2 \ddagger}$

\begin{abstract}
Laboratory of Cell Therapies and Respiratory Medicine, Department of Medical and Surgical Sciences for Children and Adults University Hospital of Modena and Reggio Emilia, Modena, Italy, ${ }^{2}$ University Hospital of Modena, Respiratory Diseases Unit, Department of Medical and Surgical Sciences, University of Modena Reggio Emilia, Modena, Italy, ${ }^{3} \mathrm{Clinical}$ and Experimental Medicine PhD Program, University of Modena Reggio Emilia, Modena, Italy, ${ }^{4}$ University of Groningen, Departments of Pathology \& Medical Biology and Pulmonology, GRIAC Research Institute, University Medical Center Groningen, Groningen, Netherlands, ${ }^{5}$ IdISBa (Institut d'Investigacio Sanitaria Illes Balears), Palma de Mallorca, Spain, ${ }^{6}$ Laboratory of Cellular Therapy, Program of Cell Therapy and Immuno-Oncology, Division of Oncology, Department of Medical and Surgical Sciences for Children \& Adults, University Hospital of Modena and Reggio Emilia, Modena, Italy, ${ }^{7}$ Department of Medicine, University of Vermont, Burlington, VT, United States, ${ }^{8}$ Oncology Unit, University Hospital of Modena, University of Modena and Reggio Emilia, Modena, Italy
\end{abstract}

Idiopathic pulmonary fibrosis (IPF) is one of the most aggressive forms of idiopathic interstitial pneumonias, characterized by chronic and progressive fibrosis subverting the lung's architecture, pulmonary functional decline, progressive respiratory failure, and high mortality (median survival 3 years after diagnosis). Among the mechanisms associated with disease onset and progression, it has been hypothesized that IPF lungs might be affected either by a regenerative deficit of the alveolar epithelium or by a dysregulation of repair mechanisms in response to alveolar and vascular damage. This latter might be related to the progressive dysfunction and exhaustion of the resident stem cells together with a process of cellular and tissue senescence. The role of endogenous mesenchymal stromal/ stem cells (MSCs) resident in the lung in the homeostasis of these mechanisms is still a matter of debate. Although endogenous MSCs may play a critical role in lung repair, they are also involved in cellular senescence and tissue ageing processes with loss of lung regenerative potential. In addition, MSCs have immunomodulatory properties and can secrete anti-fibrotic factors. Thus, MSCs obtained from other sources administered systemically or directly into the lung have been investigated for lung epithelial repair and have been explored as a potential therapy for the treatment of lung diseases including IPF. Given these multiple potential roles of MSCs, this review aims both at elucidating the role of resident lung MSCs in IPF pathogenesis and the role of administered MSCs from other sources for potential IPF therapies.

Keywords: cell based therapy, extracellular matrix, exosomes, idiopathic pulmonary fibrosis, mesenchymal stem cells 


\section{INTRODUCTION}

Idiopathic pulmonary fibrosis (IPF) is a chronic progressive fibrosing lung disease of unknown cause that occurs primarily in older adults with a median survival of 3 years after diagnosis. It is diagnosed by clinicopathological criteria, including (Raghu et al., 2011) the radiographic and/or histological hallmark pattern of usual interstitial pneumonia (UIP). Prognosis remains extremely poor with most patients dying from progressive respiratory failure, often precipitated by acute events, namely disease exacerbations (Collard et al., 2016). As a therapeutic strategy, the two antifibrotic drugs Pirfenidone and nintedanib can slow down the respiratory functional decline of IPF patients, and according both the real-word data and randomized controlled trials, such as CAPACITY and ASCEND improve survival in patients (Guenther et al., 2018; Jo et al., 2017). Despite that, IPF still has a high mortality rate and that survival times are quite heterogenous (Noble et al., 2011; Glaspole et al., 2014; Sgalla et al., 2016; Richeldi et al., 2017; Lederer and Martinez, 2018; Cerri et al., 2019).

The pathogenesis of IPF is complex and far from being fully understood (Ley et al., 2011; Ryu et al., 2014). Current hypotheses center on alveolar epithelial and vascular endothelial injuries that lead to fibroblast activation, abnormal matrix collagen deposition (King et al., 2011; Bellaye and Kolb, 2015; Bitterman, 2018), aberrant repair mechanisms, inflammation, and a regenerative deficit of the alveolar tissue (Noble et al., 2011; Betensley et al., 2016). According to more recent studies, the onset and progression of IPF is due to the aberrant damage and activation of alveolar epithelial cells (AECs) that lead to the secretion of profibrotic, coagulant, and inflammatory cytokines controlling the proliferation, activation and differentiation of fibroblasts into myofibroblasts and the consequent secretion and deposition of extracellular matrix (ECM) proteins (Selman and Pardo, 2020). These mechanisms translate into increased overall lung structural rigidity and thickening of the alveolarcapillary barrier with decline in alveolar gas exchange function. Since current evidence indicates epithelial cells as primers of disease and myofibroblasts as the key effectors in perpetrating fibrosis, recent investigations have focused on the cellular origin of the myofibroblasts including the potential role of resident mesenchymal progenitors as major source (Selman and Pardo, 2020). In particular, among myofibroblasts precursors, lung resident MSCs (LRMSCs) have recently been gaining attention as to whether their aberrant behavior might be crucial in the fibrotic process (Agha et al., 2014; Enes et al., 2017; Cao et al., 2019). While research on resident lung MSCs as key protagonists in the pathogenesis of lung fibrosis is still emerging, there are many studies focusing on different roles of MSCs obtained from other sources outside of the lung namely their therapeutic potential given a range of immunomodulatory and anti-inflammatory properties (Uccelli et al., 2008; Mastrolia et al., 2019). To this purpose, a large number of pre-clinical investigations demonstrated efficacy of systemically or intratracheally administered MSCs obtained from bone marrow, adipose tissue, and other sources in a range of lung injury models. This has led to consideration and initial clinical investigations in IPF and other chronic lung diseases. (Weiss and Ortiz, 2013; Burgess and Irene, 2019). In parallel, a growing number of clinical investigations have been exploring systemic MSCs administration for the potential treatment of acute lung injury including the acute respiratory distress syndrome (ARDS) as well as most recently as potential treatment of COVID-19 respiratory failure (Golchin et al., 2020; Meng et al., 2020; Zumla et al., 2020). Although the mechanism of actions of MSCs in lung diseases have not yet been fully elucidated, and are likely to be different depending on the disease, the beneficial effects seem to be mainly dependent on paracrine mechanisms including release of bioactive molecules (soluble proteins, nucleic acids, lipids) and extracellular vesicles (EVs) (Kim et al., 2012; Chen et al., 2018; Cruz and Patricia, 2020; Harrell et al., 2019; Beer et al., 2017; Vizoso et al., 2017). In general, the EVs consists of exosomes, micro-vesicles ( $\mathrm{MVs}$ ), and apoptotic bodies that can be discriminated by their size and origin in the cells. Exosomes contain several molecules such as protein, lipids, mRNA, miRNA (Valadi et al., 2007), mitochondrial DNA (Guescini et al., 2010) and others non coding RNAs (Ferguson and Nguyen 2016). MSCs-derived exosomes have demonstrated immunoregulatory (Dabrowska et al., 2021), angiomodulatory (Lee et al., 2013; Alcayagamiranda et al., 2016) and anti-apoptotic effects that control tissue repair and regeneration (Vishnubhatla et al., 2014; Lou et al., 2017) in both tissue culture and animal models. This includes a growing literature in which MSCsderived EVs can be as effective as the MSCs themselves in preclinical models of lung injuries (Cruz and Patricia, 2020; Harrell et al., 2019; Beer et al., 2017; Vizoso et al., 2017).

In this dualistic scenario, the aim of this review is to explore the updated evidence on the molecular mechanisms of IPF from the alveolar epithelium damage to fibrotic changes, highlighting the role of resident lung MSCs as emerging key cellular determinant in IPF onset and progression and providing an overview of the potential role of MSCs from different sources and their secretome in cellbased therapies for lung fibrosis.

\section{KEY MOLECULAR MECHANISMS OF IDIOPATHIC PULMONARY FIBROSIS AS AN EPITHELIUM DRIVEN DISEASE}

Nowadays IPF is described as an epithelium-driven disease characterized by aberrant functional epithelium due to aging and exposure to alveolar injuries in combination with compromised lung tissue regeneration, leading to abnormal repair with an imbalance between profibrotic and antifibrotic factors. Notably, this aberrant reparative mechanism leads to an increased fibroblast proliferation and myofibroblast activity 
resulting in ECM deposition. It is known that the lung consists of quiescent tissue with little cell turnover at rest, compared for example to intestinal epithelial tissues. However, after injury it has the capability to efficiently regenerate the damage in both airway and alveolar niches (Beers and Morrisey, 2011). In normal lung, alveolar injuries are followed by depletion of type 1 alveolar epithelial cells (AECI) that are located at the interface with vascular endothelium and participate in alveolar gas exchange function. The lack of AECI is compensated by the alveolar epithelial cell 2 (AECII) that normally secrete the pulmonary surfactant to maintain the surface tension, but also have capacity to proliferate and differentiate into AECI, restoring the alveolar epithelium once injured (Fomby et al., 2010). The abnormal reparative response to injury of epithelial cells in IPF represents an initial and crucial mechanism of disease. The epithelial secretion of pro-fibrotic factors promotes fibroblast migration, proliferation, activation and differentiation into myofibroblasts with deposition of exaggerated ECM and subsequently distortion of the lung architecture. Several mechanisms and molecular pathways in lung IPF epithelium have been demonstrated to contribute to the development of the disease. Among these, abnormal AECII hyperplasia in response to injury results in the formation of mucus-filled microcystic structures that can evolve into macrocysts, compromising epithelial differentiation and alveolar epithelial cell function (Seibold et al., 2013; Vaughan et al., 2015). Indeed, in the damaged alveolar epithelium of IPF lungs the process named "bronchiolization" leads to migration of abnormal basal cells with accumulation of nuclear $\beta$-catenin (basal-cell hyperplasia) from adjacent bronchioles toward areas of alveolar injury colonizing them leading to aberrant reepithelialization and contributing to disease progression. The integrity of the alveolar epithelium is severely disrupted in IPF lungs where abnormal epithelium covering the fibroblastic foci displayed a bronchiolar immunophenotype (Chilosi et al., 2003) Different works support the concept that bronchiolar abnormalities in IPF are due to changes in lung epithelial cell differentiation (Plantier et al., 2011). In particular, abnormal basal cells may differentiate into nonciliated Club cells or ciliated FoxJ1 expressing bronchial cells, resulting in bronchiolization of damaged alveoli. Thus, bronchiolization of enlarged alveolar ducts, cysts and alveoli, results in the typical honeycombing that can be seen in the lung of IPF patients (Plantier et al., 2011).

Recently, it has been shown that the oncogene epithelial cell transforming sequence 2 (ECT2), a guanine nucleotide exchange factor (GEF) for Rho GTPases, is upregulated in hyperplastic AECII of IPF patients, and can contribute to the hyperplastic and proliferative lung epithelial cell phenotype (Ulke et al., 2019). In addition, pro-fibrotic mediators including transforming growth factor beta-1 (TGF- $\beta 1$ ), platelet-derived growth factor (PDGF), tumor necrosis factor (TNF), endothelin-1, connective tissue growth factor (CTGF), osteopontin, and CXC chemokine ligand 12 (CXCL12) (Pardo et al., 2005; Selman and Pardo, 2020) are up-regulated in AECs and can contribute to the progression of fibrosis and aberrant extracellular matrix remodeling.

\section{TGF $\beta$ SIGNALING AND CROSS-TALK WITH WNT AND SONIC HEDGEHOG PATHWAYS ACTIVATED IN EPITHELIAL CELLS OF IDIOPATHIC PULMONARY FIBROSIS PATIENTS}

TGF $\beta$ can be considered a key regulator of fibrotic process favoring migration, proliferation, and activation of fibroblasts, differentiation into myofibroblasts, and deposition of ECM proteins (Meng et al., 2016; Horowitz and Thannickal, 2019). Indeed, TGF $\beta$ receptor complex activation leads to downstream canonical (SMAD2 \& 3) (Massagué, 2014) and non-canonical signaling cascades (PI3K, MEK, mTOR, etc) (Hu et al., 2018), which orchestrate the transcription of profibrotic mediators, growth factors, microRNAs, and ECM proteins (Andrianifahanana et al., 2013). Furthermore, cross-talks exists with TGF $\beta 1$ signaling and pathways overexpressed by epithelial cells of IPF patients such as Wnt and Sonic hedgehog (Shh) (Bolaños et al., 2012; Cigna et al., 2012). Zhou et al. (2012) found that TGF- $\beta 1$ and $\mathrm{Wnt} / \beta$-catenin crosstalk played a role in IPF pathogenesis since TGF- $\beta 1$ activate $W n t / \beta$-catenin pathway and together with $\mathrm{Wnt} / \beta$-catenin signaling induced epithelialmesenchymal transition and myofibroblast activation (Zhou et al., 2012). Hasaneen et al.; found that TGF- $\beta 1$ triggered the release of a glycosylated transmembrane protein named EMMPRIN (Extracellular Matrix metalloproteinase Inducer) that increases the expression of some matrix metalloproteinase (MMP) and activates $\beta$-catenin/canonical Wnt signaling pathway. Here, EMMPRIN overexpression led to an antiapoptotic and pro-fibrotic phenotype in lung fibroblasts of IPF patients (Hasaneen et al., 2016). Indeed, ICG-001, an inhibitor of T-cell factor $(\mathrm{TCF}) / \beta$-catenin transcription, has been shown to repress TGF $\beta 1$-induced EMT and reverse pulmonary fibrosis in mice (Henderson et al., 2010). More recently, it was demonstrated that chronic Wnt/ $\beta$-catenin activity in the IPF lung increased AECII senescence, leading to further progenitor cells dysfunction and impaired lung repair (Lehmann et al., 2020). In contrast, previous studies have shown that a particular lineage of Wnt responsive alveolar epithelial progenitor cells within the AECII population acted as a central player in lung regeneration after acute injury, being able to self-renew (Zacharias et al., 2018). Bolanos et al. (2012) found that Shh pathway is activated in IPF lungs and might contribute to IPF pathogenesis by increasing fibroblast proliferation, migration and ECM production. They measured the expression of Shh, Patched-1, Smoothened, and transcription factors glioma-associated oncogene homolog GLI1 and GLI2 in IPF and normal lungs finding that most of them were overexpressed in IPF (Bolanos et al., 2012). Further, TGF- $\beta 1$ modulates the expression of key components of the hedgehog pathway in lung fibroblasts, while the activity of the transcription factor GLI from the primary cilium is required to induce and maintain myofibroblast differentiation (Cigna et al., 2012). 


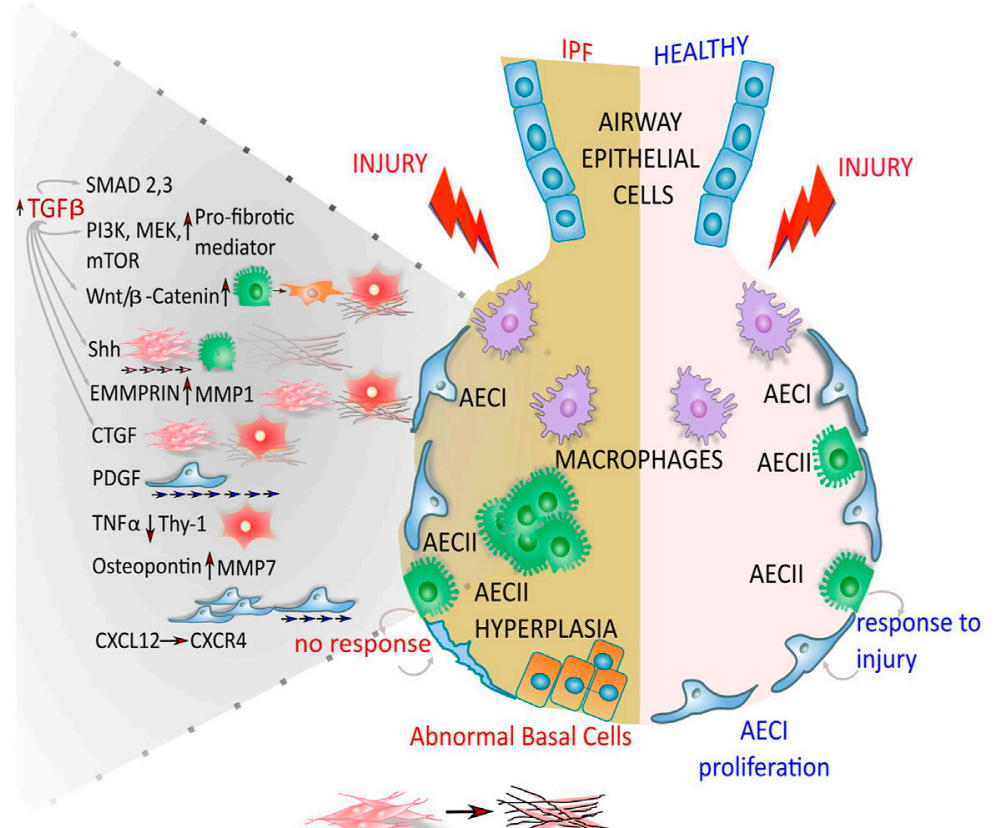

Fibroblast matrix deposition proliferation

$\begin{array}{cc}\text { LUNG } & \text { LUNG } \\ \text { BIOMECHANICS } & \text { BIOMECHANICS } \\ \text { PROPERTIES X } & \text { PROPERTIES }\end{array}$

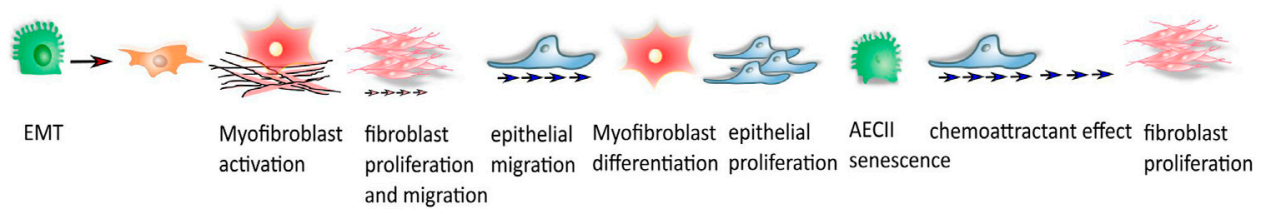

FIGURE 1 | Different response from the epithelium to lung injury in normal and IPF lung. In normal lung, the depletion of alveolar epithelial cells 1 (AECI) that play a pivotal role in gas exchange with the adjacent blood vessels after injuries, is compensated/replenished by/upon the differentiation of alveolar epithelial cells 2 (AECII) in $\mathrm{AECl}$, restoring the alveolar epithelium. In lung epithelium of IPF patients, the regeneration of AECI by AECll progenitors is compromised, leading to impaired alveolar reepithelialization. Together with the aberrant repair mechanisms the AECs start to secrete pro-fibrotic mediators that through different molecular pathway and downstream effectors lead to fibroblast migration, proliferation, activation and differentiation into myofibroblasts with deposition of exaggerated ECM that drastically compromise the lung biomechanics properties.

Among other pathways involved, PDGF showed mitogenic and chemoattractant effects on fibroblasts while connective tissue growth factor (CTGF) was found to promote the progression of fibrosis either activating fibroblasts or through TGF- $\beta$ pathway (Allen and Spiteri 2002).

\section{TNF- $\alpha$, OSTEOPONTIN, CXCL12, AND MATRIX METALLOPROTEASES INVOLVEMENT IN THE IDIOPATHIC PULMONARY FIBROSIS PATHOGENESIS}

Tumor necrosis factor-alpha (TNF- $\alpha$ ) was found to cause loss of fibroblast Thy-1 surface expression, thus contributing to myofibroblast differentiation (Kis et al., 2011). Selman and
Pardo reported that osteopontin acted on both neighboring epithelial cells and fibroblast to trigger a migratory and proliferative phenotype (Selman and Pardo, 2020). Recently CXCL12 was reported to act on CXCR4, which is expressed in advanced form of interstitial lung diseases, particularly when cystic lesions are present (Jaffar et al., 2020). Furthermore, matrix metalloproteases (MMPs) showed to play a role in the progression of IPF. Particularly, MMP1 and MMP7 are strongly expressed in the IPF epithelial cells compared to the epithelium in normal tissue. MMP1 increases cell proliferation and protects epithelial cells from apoptosis (Herrera et al., 2013), while MMP7 is involved in the fibrotic response upon osteopontin (Pardo et al., 2005). Figure 1 summarizes the different pathways involved in alveolar epithelial response to lung injury in normal and IPF lung. 


\section{HIPPO PATHWAY IN THE LUNG FIBROSIS PROGRESSION}

It has been reported that Yes-associated protein (YAP) and the transcriptional coactivator with PDZ-binding motif (TAZ) that belong to the Hippo pathway are aberrantly activated in lung fibrosis. In particular, YAP/TAZ that act as sensors of mechanical forces in cell microenvironment, are activated in fibroblasts of fibrotic lung due to ECM stiffness thus subjected to mechanical stretch, leading to the secretion of profibrotic mediators and ECM proteins (Noguchi et al., 2018; Marchioni et al., 2020). This feedforward loop enhances the lung fibrosis progression. Indeed, in epithelial cells, YAP/TAZ are also activated with the disruption of cell polarity and increased ECM stiffness in fibrotic tissues (Noguchi et al., 2018). To this purpose, (Xu et al., 2016b) after performing single-cell RNA sequencing of epithelial cells from IPF patients (Xu et al 2016), through Pathway analysis showed that the YAP/TAZ, TGF- $\beta$, Wnt, and PI3K signaling pathways were aberrantly activated in epithelial cells of IPF lung patients (Gokey et al., 2018). They suggested that YAP interacted with mTOR/PI3K/AKT signaling increasing the proliferation and migration of lung epithelial cells. Then, YAP/TAZ pathway contributes to the pathogenesis of IPF in lung fibroblasts and epithelial cells. Recently, Sun and collaborators have shown that Hippo/TAZ signaling also affects the regenerative capacity of AECII progenitors. TAZ also named WW Domain Containing Transcription Regulator 1(WWTR1) plays a crucial role in AECII to AECI differentiation and thus contribute to the maintenance of alveolar integrity after injury. Notably, conditional deletion of TAZ in AECII dramatically reduced AECI regeneration during recovery leading to exacerbated alveolar lesions and fibrosis in a bleomycin induced lung injury model. In addition, TAZ signaling can activate pro-fibrotic responses in fibroblasts (Sun et al., 2019).

Despite all these insights, the complete molecular mechanisms behind/underlying the differentiation of AECII in AECI after acute lung injury and how this is dysregulated in IPF are far from being fully understood.

\section{CELLULAR SENESCENCE, GENETIC AND ENVIRONMENTAL RISKS IN THE PATHOGENESIS OF IDIOPATHIC PULMONARY FIBROSIS}

As described above, epithelial damage and activation can drive myofibroblasts proliferation and the release of pro-fibrotic factors. What causes initial epithelial damage during the onset of IPF is not fully understood. To date, an integral model of IPF pathogenesis has been proposed where the presence of rare or common gene variants (genetic), cellular senescence and epigenetic reprogramming, converge to the initiation and progression of the disease (Michalski and Schwartz, 2020; Selman and Pardo, 2020). Indeed, agingassociated alterations as mitochondrial dysfunction and altered proteostasis could promote epithelial and fibroblast senescence in IPF lungs through the loss of proteome integrity and the shortening of telomeres (Mora et al., 2017; Lederer and Martinez, 2018). Cellular senescence leads to replicative arrest, apoptosis resistance, and the acquisition of a senescence-associated secretory phenotype (SASP), that involves the release of several inflammatory, growthregulating and tissue-remodeling factors and could thus contribute to pro-fibrotic responses (Kirkland and Tchkonia, 2017). Hence, it has been shown that the epithelial cells from IPF lungs strongly expressed cellular senescence markers p16 and p21 together with an increased secretion of SASP factors as insulin growth factor binding proteins (Igfbp) 3, 4 and 7 and MMP 3, 12 and 14 (Lehmann et al., 2017). Then, cellular senescence, might lead both to exhaustion of stem/progenitor cell renewal (dysfunction) with loss of regenerative abilities and to the secretion of pro-inflammatory and matrix-remodeling cytokines, such as IL-6, TGF- $\beta$, and matrix metalloproteases related to SASP, thus perpetrating fibrosis (Pardo and Moisé $s$ Selman, 2021). Some of the mechanisms that have been shown to induce AECII senescence as driver of IPF progression involve the overexpression of $\mathrm{Wnt} / \beta$-catenin signaling, DNA damage and telomere shortening (Mora et al., 2017). Recently, it has been demonstrated that loss of PTEN (phosphatase and tension homolog deleted on chromosome ten) triggers senescence in AECs through the activation of the protein kinase B (Akt) signaling pathway leading to a reduction of the autophagy. In particular, in a murine model of bleomycin induced AECs senescence, repression of Akt2 with the pharmacological inhibition of the Akt pathway (LY294002 and MK2206), resulted in ameliorating fibrotic lesions. The cellular senescence in IPF lungs was then found to be modulated by Akt/PTEN pathway (Qiu et al., 2019). Recently, Yao and collaborators have shown the transcriptomic features of cellular senescence characterizing the AECII isolated from IPF lung tissue. In particular, they showed how the conditional loss of Sin3a in adult mouse brought to p53dependent cellular senescence of AECII, cell depletion, and spontaneous and progressive pulmonary fibrosis. The authors suggested that progressive fibrosis might be caused by senescence rather than loss of AECII and that targeting of p53 could block fibrogenesis (Yao et al., 2020). To this purpose, with the advanced technology of single-cell RNAseq, Adams and collaborators identified a new population of IPF lung epithelial cells that was transcriptionally distinct from any epithelial cell type previously described in the lung, named aberrant basaloid cells, characterized by senescence-related genes including CDKN1A, CDKN2A, CCND1, CCND2, MDM2, and GDF15 (Adams et al., 2019). Besides the direct role of senescence of epithelial cells in the progression of IPF, it has been demonstrated that senescence of lung fibroblasts might decrease the AECII proliferation and promote migration in wound healing, affecting the re-epithelialization process after injury in IPF lung (Blokland et al., 2020). It has been widely demonstrated that genetic susceptibility together with the environmental risks play a pivotal role in disease initiation and progression in both sporadic and familial IPF. In this context, the most validated and strongest genetic risk factor for both familial and sporadic IPF, is represented by the single 
nucleotide polymorphism rs35705950 in the promoter region of the mucin 5B (MUC5B) gene (Steele et al., 2011; Allen et al., 2017; Allen et al., 2020). Normally, together with mucin 5AC (MUC5AC), MUC5B plays a crucial role in the muco-ciliary clearance (MCC) that is essential for removing inhaled debris and pathogens in the normal lung homeostasis (Roy et al., 2013; Bonser and Erle 2017). In vivo studies have demonstrated that full-length murine MUC5B overexpression in AECII of two lines of $\mathrm{C} 57 \mathrm{BL} / 6$ mice resulted in muco-ciliary clearance dysfunction thus worsening bleomycin-induced lung fibrosis (Hancock et al., 2018). Indeed, in genetically susceptible individuals bearing the rs35705950 SNP that cause MUC5B overexpression and impaired MCC, it might happen that exposure to inhaled pro-fibrotic particles could compromise the epithelial repair response to cell injury (Ley et al., 2017). Genome wide-association studies have revealed several common and rare variants associated with sporadic and familial IPF (Fingerlin et al., 2013; Allen et al., 2017; Allen et al., 2020; Dressen et al., 2018). To this purpose, the common genetic variants associated with IPF are represented by gene involved in the airway mucin production (MUC5B, MUC2), cell-cell adhesion (DSP, DPP9) playing a critical role in the maintenance of epithelial integrity, innate and adaptive immune response (Toll-Like receptor signaling, TOLLIP, TLR3), cytokine and growth factor signaling (IL1RN, IL8, IL4, TGF $\beta 1$ ), telomere maintenance (TERT, OBFC1) and cell cycle regulation (KIF15, MAD1L1, CDKN1A, TP53) (Michalski and Schwartz, 2020).

Rare variants of genes encoding proteins involved in telomere biology and maintenance have been identified in about $30 \%$ of patients with familial IPF whose AECII are characterized by short telomeres and proteins for surfactant production and secretion. These proteins include TERT, TERC (telomerase RNA component) TINF2 (TERF1 interacting nuclear factor 2), DKC1 (dyskerin), RTEL1, PARN (poly(A)-specific ribonuclease) and NAF1 (nuclear assembly factor 1 ribonucleoprotein) (Kropski et al., 2014; Kropski et al., 2015; Alder et al., 2015; Stuart et al., 2015; Stanley et al., 2016), SFPTA1, SFPTA2, SFPTC (surfactant protein A1, A2, C) and ABCA3 (ATP Binding Cassette Subfamily A Member 3) (Nureki et al., 2018; Doubková et al., 2019; Takezaki et al., 2019).

Finally, as mentioned above there are environmental risks such as cigarette smoke, inhalation of wood and metal dust, and other exposures that might contribute to the onset and progression of IPF, causing injury in the "genetically susceptible" patients (Barczyk et al., 2015; Phan et al., 2020; Shull et al., 2020). Indeed, the environmental risks might result in epigenomic modifications, with the alteration in key genes regulation contributing to the pathogenesis of IPF. To this purpose, exposure of cigarette smoke (CS) triggers DNA damagerelated chromatin binding changes, and alterations in DNA methylation, influencing gene transcription and the downstream response of cells to injury (Vaz et al., 2017). Overall, however, the mechanisms and the correlation between environmental risk factors, genetic predisposition, aging and IPF pathogenesis need to be further elucidated.

\section{THE EFFECT OF AGING ON MESENCHYMAL STROMAL/STEM CELLS}

The cellular senescence of MSCs is a cellular mechanism that compromises their regenerative potential involving the oxidative state of the cell and mitochondrial dysfunction (Li Y et al., 2017). Despite lack of complete understanding of the molecular mechanisms and signaling pathways of senescence in MSCs, the senescence-associated phenotypes are characterized by an increase in the SA- $\beta$-gal activity, in the G1 cell cycle arrest, in the reactive oxygen species (ROS) production and expression of p53 and p21 (Jiang et al., 2008) and in a compromised autophagy process. One effect of MSCs aging can be seen in their decreased osteogenic activity. The molecular pathway behind the osteogenic activity is related to the expression of the transcription factor RUNX2/CBFA1 and the PI3K-AKT pathway that both decrease with age (Atashi et al., 2015). Additionally, it has been demonstrated that the adipogenic potential of MSCs tend to decline with aging and after different passages in in vitro culture mediated in part through the PPAR $\gamma$ modulation, an adipogenicspecific transcription and cross-talk with $\mathrm{Wnt} / \beta$-catenin signaling pathway (Xu C et al., 2016).

Cellular senescence leads to replicative arrest, apoptosis resistance, and the acquisition of a senescence-associated secretory phenotype (SASP), that involves the release of several inflammatory, growth-regulating and tissue-remodeling factors and could thus contribute to pro-fibrotic responses (Kirkland and Tchkonia, 2017). Then, cellular senescence, might lead both to exhaustion of stem/progenitor cell renewal (dysfunction) with loss of regenerative abilities and to the secretion of pro-inflammatory and matrix-remodeling cytokines, such as IL-6, TGF- $\beta$, and matrix metalloproteases related to SASP, causing persistent fibrosis. (Pardo and Moisé s Selman, 2021). Indeed, a crucial mechanism that leads to MSCs senescence is the oxidative stress that leads to the production of free radicals/ROS (reactive oxygen species) the majority of which are produced by the mitochondrial respiratory chain (Liu et al., 2020). From a molecular point of view the p38/MAPK axis triggers MSCs senescence through ROS production and accumulation initiating the oxidative process that can lead to mitochondrial dysfunction, DNA damage and protein damage. In the endoplasmic reticulum (ER) take place correct folding and assembling of the proteins into their native conformation prior to be transported to intracellular organelles or cell surface. In general, during the ER stress the correct protein folding is impaired and the unfolded or misfolded proteins accumulate in the ER lumen compromising the ER homeostasis. Then, the accumulation of aberrant folded proteins activates as a cellular protective mechanism, the unfolded protein response (UPR) ameliorating cell hemostasis and survival during ER stress process. (Schröder and Kaufman, 2005; Cao and Kaufman, 2012). Indeed, it has been demonstrated that accumulation of misfolded, or unfolded, proteins into the lumen of ER might contribute to the progression of age-related diseases (Powers et al., 2009; López-Otín et al.,). Then, the oxidative stress, with compromised mechanism of UPR, might cause aging in MSCs 
affecting their cell functions and survival (Geissler et al., 2013; Wang et al., 2018). Recently, it has been demonstrated that a deficiency in the UPR lead to inactivation of ATF6, which can contribute to MSCs aging (Wang et al., 2018). In human MSCs, ATF6 is involved in cellular proteostasis, the process responsible for the preservation of a functional proteome and telomere shortening. The inactivation of ATF6 cause the accumulation of protein aggregates and compromise the integrity of various membrane organelles (Wang et al., 2018).

Indeed, these aging-associated alterations, including mitochondrial dysfunction and altered proteostasis, can also promote epithelial and fibroblast senescence in IPF lungs (Lederer and Martinez, 2018; Mora et al., 2017). Conceivable strategies to prevent aging in MSCs, for example genetic engineering through the knockdown of the tumor suppressor p16INK4a/CDKN2A (p16, cyclin-dependent kinase inhibitor 2A, CDKN2A) might lead to increase of proliferation rate and clonogenicity of MSCs (Gu et al., 2012). However, these might also increase the tumorigenesis risks. Finally, the use of growth factors such as exogenous FGF-2, PDGF and EGF have been demonstrated to reduce MSCs senescence and increase proliferation (Gharibi and Hughes, 2012). These might also be potential therapeutic interventions.

\section{THE ROLE OF RESIDENT LUNG FIBROBLASTS AND BONE MARROW PROGENITOR CELLS IN PULMONARY FIBROSIS}

Resident lung fibroblasts represent key effector cells in IPF pathogenesis since under the action of TGF- $\beta$ can proliferate and differentiate into myofibroblasts promoting fibrogenesis and impairing normal alveolar epithelial repair in response to damage (David and Cory, 2017; Chanda et al., 2019). Here, the resident fibroblasts increase the synthesis of collagen and mesenchymal proteins, such as Vimentin and $\alpha$-SMA with the activation of $\mathrm{Wnt} / \beta$-catenin axis favoring the progression of IPF (Shi et al., 2017). Then, myofibroblasts, expressing $\alpha$-SMA, trigger ECM accumulation and deposition with an increase in the structural rigidity, decrease in contractility of lung tissue, and impaired support of alveolar repair (Zhang et al., 1996; Wu and Tang, 2021). According to recent studies, it has been shown that there are several populations of resident lung fibroblasts including fibroblasts localized in the lung interstitium adjacent to alveolar epithelial cells and lipofibroblasts, mainly characterized by neutral lipids, located adjacent to AECII. Lipofibroblasts are implicated in alveolar maturation and surfactant production as well as FGF10 secretion, and have been shown to modulate the epithelial stem-cell niche in adult mouse lungs (Alam et al., 2015; Agha et al., 2017). These lipofibroblasts are characterized by specific markers such as Sca-1, CD248 (Bartis et al., 2016) and PDGFRa (Iwayama et al., 2015; Wang et al., 2017). Particularly, PDGFRa allows the discrimination between interstitial resident fibroblasts and lipofibroblasts from pericytes, mesenchymal cells closely related to vascular smooth muscle cells (VSMCs) that underlie and envelop capillaries, forming focal contacts with adjacent endothelial cells (Green et al., 2016). Recent studies of lineage tracing revealed that PDGFRa-expressing interstitial fibroblasts and/or lipofibroblasts can each differentiate into myofibroblasts after lung injury and that myofibroblast to lipofibroblast transdifferentiation is required for fibrosis attenuation in the mouse lung (El Agha et al., 2017).

As myofibroblasts represent key effector cells in lung fibrosis due to deposition of collagen and formation of scar tissue, their cellular origin and potential precursors have been extensively studied (Hinz et al., 2007; Fernandez and Oliver, 2012; BochatonPiallat et al., 2016; Horowitz and Thannickal, 2019). In this scenario, several population have been analyzed: 1) resident lung fibroblasts that under the influence of the profibrotic microenvironment directly differentiate into myofibroblasts (Phan 2002), 2) epithelial cells that lose their characteristic markers (such as E-cadherin and zona occludens-1) and acquire mesenchymal properties (such as fibroblast-specific protein-1 and a-SMA expression) in a process named epithelial-mesenchymal transition (EMT) (Willis et al., 2005; Kim et al., 2006) 3) bone marrow (BM)-derived cells as circulating fibrocytes (Phillips et al., 2004; Moore et al., 2005) and 4) pericytes (Scotton and Chambers, 2007; Wipff et al., 2007; Hinz, 2012; Hung et al., 2013). While more recent investigations have moved away from any significant roles of EMT or circulating fibrocytes as myofibroblast sources (Rock et al., 2011; Kleaveland et al., 2014; Barron et al., 2016; Chong et al., 2019), cell-lineage tracing experiments using reporter mouse models have focused attention on resident mesenchymal cell populations that can acquire myofibroblastic phenotype. These include:

- interstitial lung fibroblasts localized in the interstitium immediately adjacent to alveolar epithelial cells (Angeles, 2015; Barron et al., 2016),

- lipofibroblasts, that are lipid-droplet-containing interstitial fibroblasts located within close proximity to AECIIs (El Agha et al., 2017; Alam et al., 2015),

- pericytes localized within the capillary basement membrane connected to each other and with one or more endothelial cells (Marriott et al., 2014; Barron et al., 2016),

- mesothelial cells from pleural-mesothelium that line the visceral and parietal pleural surfaces (Karki et al., 2014), and

- resident lung mesenchymal progenitors (Xie et al., 2016), whose contribution in myofibroblast differentiating process seems prevalent.

Since the first isolation and characterization of LR-MSCs from human transplanted lungs, there has been increasing interest in their characterization with specific molecular markers for recognition, their exact location in the lung niche, their role in regulation of lung tissue homeostasis, and their role in the lung repair and regeneration after injury (Burgess and Irene, 2019; Sveiven and Nordgren, 2020). In particular, the expression of mesenchyme-specific t-box transcription factor (TBX4), that characterizes early mesenchyme progenitors during embryonic lung development, correlates with the activation and proliferation 
of myofibroblast accumulation in lung fibrosis. Then, in the adult lung the TBX4 positive lineage are fibroblasts, smooth muscle cells, pericytes, and endothelial cells (Xie et al., 2016). Indeed, it has been shown that the numbers of LR-MSCs decreases during experimentally induced fibrosis in mice. This cell population has also been shown to express ATP-binding cassette sub-family G member 2 (ABCG2) (Jun et al., 2011) and lineage tracing experiments revealed that ABCG2+ cells are located in perivascular regions and in proximity of AECI in the mouse lung. In a bleomycin mouse model ABCG2+ cells are amplified and significantly transform into myofibroblasts, contributing to the progression of lung fibrosis (Marriott et al., 2014). Moreover, another GLI1 (glioma-associated oncogene homolog 1) positive perivascular lung resident MSCs population has been shown to contribute to myofibroblast formation in the bleomycin pulmonary fibrosis mouse model (Kramann et al., 2015). Recently in a bleomycin mouse model, Cao et al. showed that Wnt10a had a pivotal role in pulmonary fibrosis as they found an increased expression level of Wnt10a secreted by LR-MSCs undergoing myofibroblastic differentiation. Indeed, after isolation of LR-MSCs with myofibroblast characteristics from fibrotic lungs they found an increase in Shh pathway activity in these cells. They demonstrated that the Shh/glioblastoma (Gli) pathway was a key regulator of LR-MSCs-to-myofibroblast transition in pulmonary fibrosis. Finally, they showed that the suppression of the Shh-Wnt signaling prevented myofibroblast differentiation from LR-MSCs ameliorating pulmonary fibrotic lesions (Cao et al., 2019).

Furthermore, the role of lipofibroblasts and their contribution to the myofibroblast cell population in IPF lungs have been studied in recent works. Among them, in the study from Kheirollhai and colleagues they demonstrated that the antidiabetic drug, metformin, inhibits collagen production in primary human lung fibroblasts and in ex vivo cultured human IPF model and triggers the myo-to lipofibroblast transdifferentiation leading to a recovery from fibrosis. They further demonstrated that treatment of bleomycin-injured mice with metformin resulted in a resolution of fibrosis altering the fate of myofibroblasts and enhanced their lipogenic differentiation (Kheirollahi et al., 2019). Finally, they showed that the antidiabetic drug metformin had potent antifibrotic effects in the lung, through the inhibition of TGF $\beta 1$ signaling and collagen formation together with $\operatorname{PPAR} \gamma$ signaling activation and lipogenic differentiation.

In another study from Zysman and colleagues (Zysman et al., 2020); they investigated whether the cell-cycle inhibitor p16INK4a limits lung regeneration after newborn bronchopulmonary dysplasia (BPD), that lead to the arrest of alveolar development. They found that p16INK4a decrease leads to an increase of neutral lipid synthesis promoting lipofibroblast and AECII development within the lung stem-cell niche. Indeed, they found that treatment with a $\operatorname{PPAR} \gamma$ (peroxisome proliferator-activated receptor $\gamma$ ) agonist increased lipofibroblast and AECII, restoring alveolar architecture after hyperoxia-exposure in mice (Zysman et al., 2020). Thus, the "plasticity" of myofibroblasts that are able under proper conditions and treatment to transdifferentiate back into lipofibroblasts, that contribute to the progression of IPF, provides the possibility to study novel drugs and compound to revert the fibrotic process in the lung niche.

To date, the emerging picture in the alveolar niche of IPF lung, indicates that there is a heterogenous myofibroblast population that may derive from different sources including interstitial lung fibroblasts, lipofibroblasts, pericytes, mesothelial cells and lungresident MSCs rather than from EMT processes/epithelial or BMderived cells (Figure 2).

\section{THE ROLE OF LUNG RESIDENT MESENCHYMAL STROMAL/STEM CELLS IN LUNG HOMEOSTASIS, INJURY AND REPAIR}

Adult resident stem cells are distributed in organ-specific niches which provide an appropriate microenvironment that regulates their development and functionality. Therefore, MSCs of all tissue origins have a common cellular signature even if there are also certain molecular features that seem to be organ-specific including the lung niche (Klein, 2020). In this regard, the characterization of human LR-MSCs meets the minimal suggested ISCT criteria for MSCs (Dominici et al., 2006) including expression of cell surface proteins as CD29, CD73, CD90, CD105 and CD146 (Kruk et al., 2021) besides being negative for hematopoietic markers. In vitro differentiation experiments have further demonstrated multilineage differentiation of LR-MSCs isolated from central and peripheral transbronchial biopsies, into adipocytes, osteoblasts and chondrocytes (Rolandsson et al., 2014). Nevertheless, it has been reported that LR-MSCs express higher level of FGFR2 as compared to BM-MSCs in mouse and rats. FGFR2 is bound by FGF10 leading to LR-MSCs activation and migration (Agha et al., 2014; Enes et al., 2017). To this purpose, Tong et al.; showed that in rats intratracheal administration of FGF-10 in lungs, led to LRMSCs mobilization that allowed their collection through bronchoalveolar lavage. The collected LR-MSCs were cultured in vitro and then intratracheally delivered to rats after LPSinduced lung injury with more beneficial effects as compared to BM-MSCs used as positive control (Tong et al., 2016). Then, Sveiven and Nordgren in a recent review gave an update on both differences and similarities between BM-MSCs and LR-MSCs about the surface protein expression profile, the transcriptome, proteome and secretome (Sveiven and Nordgren, 2020). In particular, both the transcriptomic data and the pathway analysis of proteomic data showed that pathways involving Wnt, elasticity, motility, MET signaling, and integrins were more up-regulated in LR-MSCs as compared to BM-MSCs. Among the differences regarding the secretome, it has been shown that BM-MSCs secreted significantly less monocyte chemoattractant protein-1 (MCP-1, CCL2), crucial for macrophage recruitment, than LR-MSCs, while no significant differences in immunosuppressive effects on lymphocytes were observed between the two cell populations (Larsson et al., 2016). In another study comparing murine LR-MSCs and BM-MSCs in 

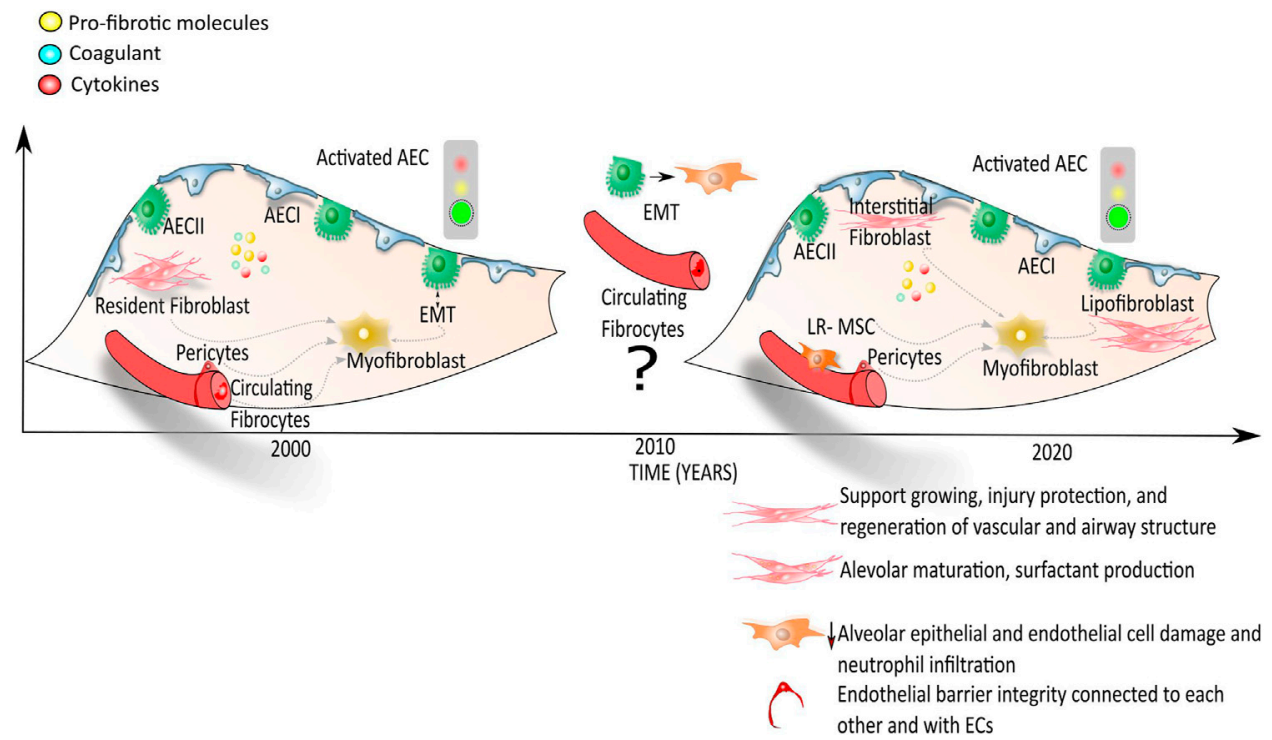

FIGURE 2 |Onset and progression of IPF: the myofibroblast in focus. According to the first hypothesis, the activation of alveolar epithelial cells (AECs) leads to the secretion of pro-fibrotic molecules, coagulant and cytokines that activate several cells from different sources: the resident fibroblast, the resident mesenchymal stromal/stem cells, the epithelial cells that undergo to the epithelial mesenchymal transition, the pericytes and the endothelial cells progenitors. These different cell types in IPF lungs may differentiate into myofibroblasts with the consequent secretion and deposition of extracellular matrix proteins followed by an overall lung structural rigidity and decline of alveolar function. According to the most recent publications (Etc 2019; Xie et al., 2016), interstitial lung fibroblasts, pericytes, lipofibroblasts, mesothelial cells and LR-MSCs, whose roles within the alveolar lung niche are list in the legend within the figure, give rise to the myofibroblast population representing the key cells for the onset and progression of fibrosis.

an elastase-injury mouse model it was suggested that LR-MSCs displayed prolonged retention in the lungs upon intravenous administration, which might be attributed to the specific expression of adhesion molecules (Hoffman et al., 2011). In a similar elastase model, effects of murine LR-MSCs, BM-MSCs and adipose derived (AD)-MSCs were compared. All sources reduced alveolar epithelial and endothelial cell damage and neutrophil infiltration and increased elastic fiber content (Figure 2). In contrast to intravenous delivery, intratracheal MSCs administration further reduced alveolar hyperinflation and collagen fiber content, while AD-MSCs and LR-MSCs showed a more significant reduction in fractional area of alveolar collapse compared to BM-MSCs (Antunes et al., 2014). In 2012 Ricciardi et al.; showed that LR-MSCs do not significantly differ from human BM-MSCs with regards to the immunophenotype, stemness gene profile and mesodermal differentiation potential. Indeed, in vitro co-culture of either LR-MSCs and BM-MSCs with activated T cells or NK cells showed the same inhibitory effect of T-cell and NK cells proliferation from the two different cell lines. They found that lung-MSCs expressed higher basal level of the nestin marker; moreover in vitro treatment with retinoic acid showed that the LR-MSCs led to higher epithelial cell differentiation and polarization compared to BM-MSCs (Ricciardi et al., 2012). The authors evaluated the effect of retinoic acid treatment in vitro on LR-MSCs and BM-MSCs after 4 weeks of RA culture and through phase-contrast microscopy. While, both LR-MSCs and BM-MSCs showed a round-cuboid shape as epithelial cells at the end of the culture, LR-MSCs cultured with RA displayed a stronger phenotype. Further, after analyzing LR-MSCs by trans epithelial electric resistance (TEER) assay after RA treatment to measure and quantify the formation of tight and adherence junctions it was found a higher polarization tendency in LR-MSCs compared to BM-MSCs (Ricciardi et al., 2012). Recently, LR-MSCs were isolated from allografts of human lung transplant recipients (Jarvinen et al., 2021). In vitro studies demonstrated that these LR-MSCs could suppress the proliferative capacity of $\mathrm{T}$ cells in response to a mitogenic or an allogeneic stimulus. The authors found that the immunosuppressive capacity of LR-MSCs was related to the secretion of $\mathrm{PGE}_{2}$ since it was shown even in the absence of direct cell contact (Jarvinen et al., 2021).

Among studies aiming at characterizing the functional role of LR-MSCs, Kruk et al.: showed that human LR-MSCs can also be forced to differentiate in vitro toward adipocytes (Kruk et al., 2021), which closely resemble lipofibroblasts that support alveolar epithelial regeneration by secretion of FGF10 and assist in surfactant production. Thus, it might be speculated that such events, depending on cues from the microenvironment, may result in improved support of alveolar repair. In vitro, LR-MSCs secrete substantial levels of HFG as well as ECM molecules such as decorin, which is known to bind and inhibit TGF- $\beta$ signaling (Kruk et al., 2021), acquiring of a role in alveolar repair. In vitro expanded LR-MSCs were also able to engraft decellularized lung tissue scaffolds and produce growth factors (Kruk et al., 2021). Concerning the role of LR-MSCs in lung pathologies and in particular in lung fibrosis several studies highlight a potential pathological role that is mediated by Wnt signaling. Cao et al. found that inhibition of the Shh-Wnt pathway in the bleomycin mouse model prevented LR-MSCs from differentiating into myofibroblasts and reduced lung fibrosis (Cao et al., 2018). Summers et al., further report in the same model that genetic 
TABLE 1 | In vitro and in vivo studies involving LR-MSCs in lung homeostasis, injury and repair.

\begin{tabular}{|c|c|c|c|}
\hline Study & Method & Source of MSCs & Outcome \\
\hline Tong et al. (2016) & Intratracheal administration to rat & LR-MSCs/BM-MSCs & $\downarrow$ inflammation after LPS-induced lung injury \\
\hline $\begin{array}{l}\text { Antunes et al. } \\
(2014)\end{array}$ & $\begin{array}{l}\text { Elastase murine model/intratracheal } \\
\text { administration }\end{array}$ & LR/AD/BM-MSCs & $\begin{array}{l}\downarrow \text { alveolar hyperinflation } \\
\downarrow \text { Collagen fibers } \\
\downarrow \text { Alveolar area collapse }\end{array}$ \\
\hline $\begin{array}{l}\text { Ricciardi et al. } \\
\text { (2012) }\end{array}$ & In vitro co-culture and RA treatment & LR-MSCs/BM-MSCs & $\begin{array}{l}\downarrow \text { T-cells/NK cells proliferation } \\
\uparrow L R-M S C s \text { polarization after RA treatment }\end{array}$ \\
\hline $\begin{array}{l}\text { Jarvinen et al. } \\
(2021)\end{array}$ & In vitro studies & $\begin{array}{l}\text { LR-MSCs/allograft of human lung } \\
\text { transplant }\end{array}$ & $\begin{array}{l}\downarrow \text { T-cells proliferation } \\
\text { †immunosuppressive capacity-PGE } 2 \text { secretion }\end{array}$ \\
\hline Kruk et al. (2021)1 & In vitro studies-differentiation & LR-MSCs & $\begin{array}{l}\uparrow \mathrm{HGF}, \uparrow \text { ECM proteins (decorin), } \uparrow \text { engraftment of decellularized } \\
\text { lung tissue scaffold }\end{array}$ \\
\hline Cao et al. (2019) & $\begin{array}{l}\text { Inhibition of Shh/WNT sigmalling.in bleomycin } \\
\text { model }\end{array}$ & Analysis on murine LR-MSCs & $\begin{array}{l}\downarrow \text { myofibroblast differentiation of LR-MSCs } \\
\text { \lung fibrosis }\end{array}$ \\
\hline $\begin{array}{l}\text { Summers et al. } \\
(2020)\end{array}$ & Knock out mouse model for MVPC & Murine MVPC-ABCG2 ${ }^{+}$cells & $\begin{array}{l}\uparrow \text { microvascular dysfunction } \\
\text { †lung fibrosis }\end{array}$ \\
\hline Jun et al. (2011) & Intravenous injection of LR-MSCs & LR-MSCs & $\begin{array}{l}\downarrow \text { bleomycin-induced fibrosis } \\
\downarrow \text { arterial hypertension (PAH) }\end{array}$ \\
\hline $\begin{array}{l}\text { Marriott et al. } \\
\text { (2014) } \\
\text { Martin et al. (2020) }\end{array}$ & $\begin{array}{l}\text { In vitro functional study/in vivo study bleomycin } \\
\text { mouse model } \\
\text { In vitro studies }\end{array}$ & $\begin{array}{l}\text { Human LR-MSCS/ } \\
\text { ABCG2 }{ }^{+} \text {MSC } \\
\text { LR-MSCs from donor and IPF } \\
\text { patients }\end{array}$ & $\begin{array}{l}\downarrow \text { LR-MSCs cell number in IPF patients } \\
\uparrow \text { pro-fibrotic reprogramming } \\
\downarrow \text { decreased genetic profile in the ox-phospho. Pathway in } \\
\text { LR_MSCs from IPF } \\
\downarrow \text { in vitro repair potential (lung epithelial wound) }\end{array}$ \\
\hline
\end{tabular}

activation of Wnt in linage labeled ABCG2 positive pulmonary mesenchymal vascular progenitor cells (MVPC) drive microvascular dysfunction and exacerbated fibrosis (Summers et al., 2021). In 2011 Jun and collaborators demonstrated that treatment of mice with bleomycin led to the decrease of endogenous LR-MSCs population identified as $\mathrm{H} 33342^{\text {low }} \mathrm{CD} 45^{\text {neg }}$ by flow cytometry and in vivo by immunostaining to detect the multidrug resistance transporter ATP binding cassette (ABCG2.) Indeed, they hypothesized that decrease in the LR-MSCs population favored the progression of fibrosis measured with Aschroft score inflammation, and pulmonary arterial hypertension (PAH). The replacement of lung resident stem cells by intravenous injection of exogenous LR-MSCs immediately after the intratracheal administration of bleomycin reduced both the bleomycin-associated fibrosis and the PAH (Jun et al., 2011). The study from Marriott et al.; described the functional role of LR-MSCs in IPF. They found that LR-MSCs were located in the distal lung and expresses ABCG2 contributing to the myofibroblast population and lung tissue remodeling in IPF. They found that in patients with IPF or ILD ABCG2 ${ }^{\text {pos }}$ cell numbers were decreased relative to control, possibly because most of them differentiated into myofibroblasts contributing to the lung remodeling during IPF (Marriott et al., 2014). In another functional study, Martin et al. compared LR-MSCs from donor and IPF patients and found that IPF derived LR-MSCs presented a decreased genetic profile in the oxidative phosphorylation pathway and had reduced potential to induce the repair of a lung epithelial wound in an in vitro indirect co-culture system (Martin et al., 2020). Thus, abnormalities in endogenous LR-MSCs may contribute to aberrant alveolar repair responses in IPF. For their use in autologous cell-based therapies, more insight into LR-MSCs function and potential abnormalities in IPF is crucial and may guide pre-conditioning strategies of LR-MSCs.
Finally, in addition to their molecular and functional properties, understanding the spatial location of LR-MSCs within the lung is crucial in order to elucidate their physiological role in maintaining lung homeostasis. Although the exact location of LR-MSCs remains under debate, recent studies found that human LR-MSCs express the so called "HOX code" characteristic of vascular wall MSCs (VWMSCs derived from the vascular wall of adult human blood vessels) therefore pointing at a vascular nature. According to this picture, LRMSCs would be located within two areas: 1 . a vascular niche situated at the perivascular space between the vessels and the surrounding tissue, and 2. an alveolar niche in close contact with the capillary endothelial cells and the alveolar epithelial cells (Steens et al., 2021).

To date, given the poor functional characterization of LRMSCs related to the bone marrow counterpart, their role in the lung homeostasis and pathologies should be inferred both from the studies published on LR-MSCs (Steens et al., 2021), and essentially from studies based on the comparison of those to BM-MSCs. Indeed, a deeper characterization of LRMSCs, with more in vitro and in vivo studies that will recapitulate both the spatial location and the functional effects of these cells in the lung would clarify their role within lung tissue microenvironment to enrich the knowledge in the LR-MSCs biology in order to perform new and effective LR-MSCs-based therapy. (Table 1).

\section{THE ROLE OF EXOGENOUSLY ADMINISTERED MESENCHYMAL STROMAL/STEM CELLS IN LUNG REPAIR AFTER INJURY}

MSCs are able to regulate the adaptive and innate immune systems by either their paracrine effect via soluble factors or 


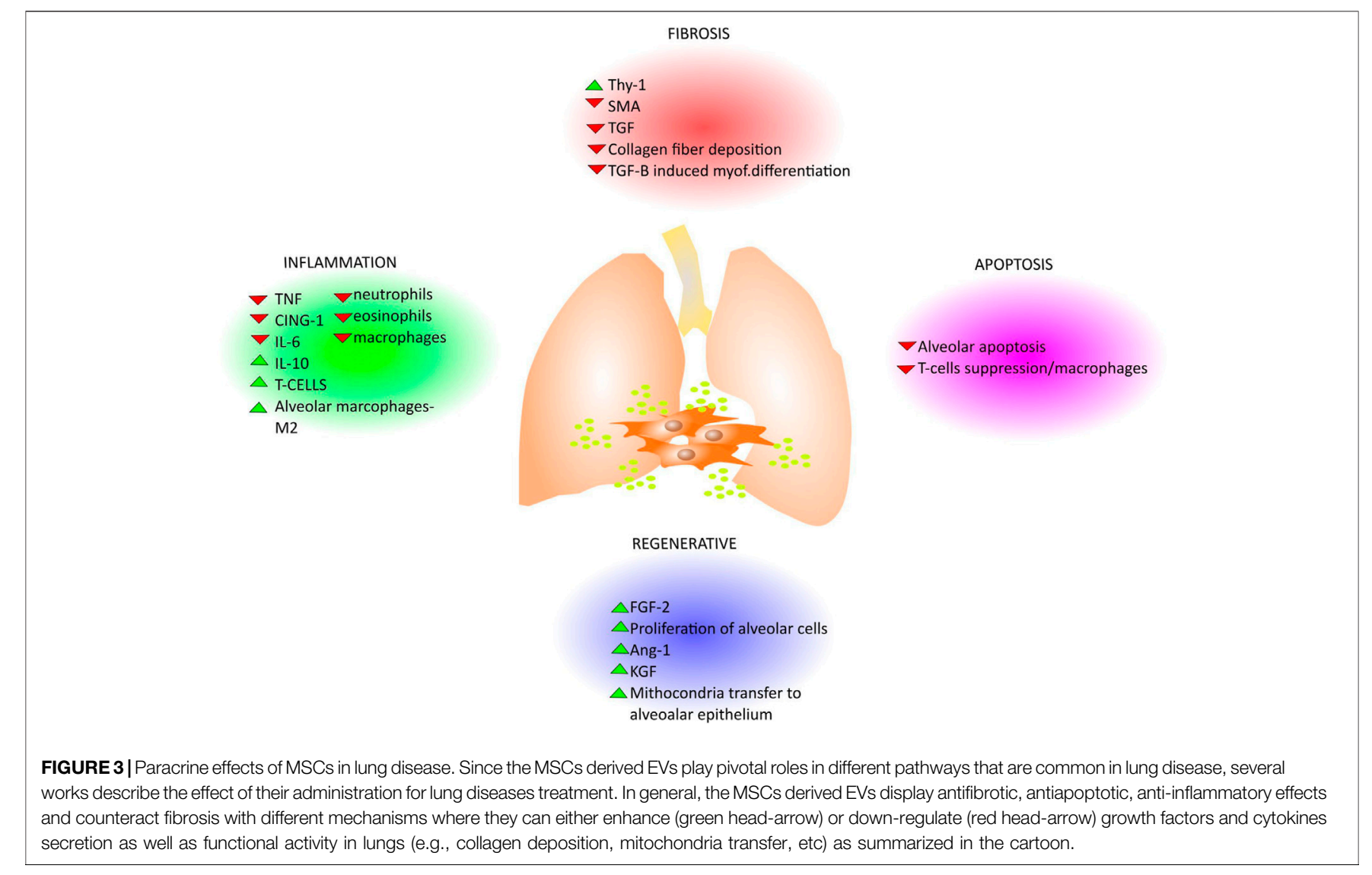

by cell-cell contact mechanisms with inhibition of T-lymphocyte proliferation, modulation of regulatory T-cells (Tregs) function, maturation of dendritic cells, reduction of B-cell activation and proliferation, inhibition of proliferation and cytotoxicity of NK cells, and stimulation of regulatory T cells (Gharibi and Hughes, 2012; Gao et al., 2016). The paracrine effect of different sources of MSCs is expressed through the secretion of soluble antiinflammatory factors including but not limited to TGF- $\beta$, hepatocyte growth factor (HGF), interleukin (IL)-10, IL-1 receptor antagonist (IL-1Ra) prostaglandin E2 (PGE2) microRNAs (Vishnubhatla et al., 2014; Gazdic et al., 2015; Maguire, 2013), and factors that drive endothelial and epithelial repair and regeneration such as angiopoetin 1 (ANGPT1), FGFs (FGF2, FGF10) keratinocyte growth factor (KGF)/FGF7, hepatocyte growth factor (HGF), epidermal growth factor (EGF) and vascular endothelial growth factor alpha (VEGFA). In addition, MSCs can modulate repair responses by the deposition and remodeling of extracellular matrix (Kruk et al., 2021) providing cues to instruct cellular behavior such as survival, migration and proliferation (Figure 3). There have been a wide range of MSCs antiinflammatory and immunomodulatory properties demonstrated in preclinical models of lung injuries including pulmonary fibrosis (Behnke et al., 2020). Although BM-derived MSCs are the most extensively investigated (Zhang et al., 2019), MSCs from other sources such as umbilical cord, placenta and adipose tissue have been studied (Aguilar et al., 2009; Yamada et al., 2004) (Table 2). As one example, in a bleomycin-induced lung injury model in mice, Moodley et al.; demonstrated that umbilical cord derived MSCs (uMSCs) can reduce lung inflammation and prevent fibrosis by up-regulating antiinflammatory modulators and downregulating both cytokine production and pro-fibrotic factor release as measured through quantitative real-time PCR from whole lung suspensions from mice at 14 days post-bleomycin (Moodley et al., 2009). Indeed, in another study using the bleomycin mouse model of lung fibrosis, placenta-derived MSCs suppressed the infiltration of neutrophils, mitigated the inflammatory response and promoted lung tissue regeneration (Cargnoni et al., 2009; Antoniou et al., 2018). However, as shown in Table 2, in most of the preclinical studies, MSCs were administered after a few hours or days following the induction of lung damage and prevented the development of fibrotic changes (Jenkins et al., 2017). In contrast, when MSCs were administered at weeks 8, 10, 12, and 14 after-BLM induction (Moeller et al., 2008), no effect on lung collagen content was found while only improvement in Ashcroft score and lung TGF- $\beta$ levels was reported. These studies mirror findings in one of the original studies on MSCs effects in the bleomycin lung model in which MSCs administration immediately after bleomycin significantly reduces inflammation, collagen deposition, and MMPs activation preventing development of fibrosis whereas delayed application decreased the inflammation but failed to reduce lung fibrosis (Ortiz et al., 2003). In another pre-clinical study Yu et al.; 
TABLE 2 | Pre-clinical applications of MSCs in lung diseases. DAB = days after bleomycin administration.

\begin{tabular}{|c|c|c|c|c|c|}
\hline Study & $\begin{array}{l}\text { Lung disease } \\
\text { model }\end{array}$ & $\begin{array}{l}\text { Type of } \\
\text { MSCs }\end{array}$ & $\begin{array}{l}\text { Source of } \\
\text { MSCs }\end{array}$ & Effect & $\begin{array}{c}\text { Timing of } \\
\text { administration }\end{array}$ \\
\hline Li et al. (2017a) & Pulmonary fibrosis & Human fpMSCs & Placenta & $\begin{array}{l}\downarrow \text { collagen deposition, } \uparrow \text { pro-fibrotic } \\
\text { cytokines }\end{array}$ & $1 \times 10^{5}$ cells-tail vein-3DAB \\
\hline $\begin{array}{l}\text { Cargnoni et al. } \\
\text { (2009) }\end{array}$ & Pulmonary fibrosis & $\begin{array}{l}\text { Murine/human } \\
\text { MSCs }\end{array}$ & Placenta & $\downarrow$ neutrophil infiltration & $\begin{array}{l}1-4 \times 10^{5} \text { cells - } \\
\text { intraper.intrajug.intratrach. }-15 \mathrm{mAB}\end{array}$ \\
\hline $\begin{array}{l}\text { Moodley et al. } \\
\text { (2009) }\end{array}$ & ARDS & Human MSCs & Umbilical cord & $\begin{array}{l}\downarrow \text { TIMP expression, } \downarrow \text { lung cytokine, } \uparrow \text { MMP } \\
\text { expression }\end{array}$ & $1 \times 10^{6}$ cells-tail vein-1DAB \\
\hline Jun et al. (2011) & Pulmonary fibrosis & Murine MSCs & Lung & $\begin{array}{l}\downarrow \text { lymphocyte and granulocyte infiltration, } \\
\downarrow \text { PAH }\end{array}$ & $1.5-2.5 \times 10^{6}$-tail vein-14DAB \\
\hline $\begin{array}{l}\text { Moodley et al. } \\
\text { (2013) }\end{array}$ & $\begin{array}{l}\text { COPD- pulmonary } \\
\text { fibrosis }\end{array}$ & $\begin{array}{l}\text { Murine/human } \\
\text { MSCs }\end{array}$ & $\begin{array}{l}\text { Bone marrow, } \\
\text { amnion }\end{array}$ & $\downarrow$ TGF- $\beta, \uparrow$ MMP-9, $\uparrow$ GM-CSF, $\uparrow$ IL-1RA & $1 \times 10^{6}$ cells-tail vein-3DAB \\
\hline $\begin{array}{l}\text { Huleihel et al. } \\
(2017)\end{array}$ & Pulmonary fibrosis & Human MSCs & Bone marrow & $\begin{array}{l}\downarrow \text { collagen deposition and CD45-positive } \\
\text { cells }\end{array}$ & $5 \times 10^{5}$ cells-tail vein-7DAB \\
\hline Ortiz et al. (2003) & IPF & Murine MSCs & Bone marrow & $\downarrow$ collagen deposition, $\downarrow$ inflammation & $5 \times 10^{5}$ cells-intrajug. 0-7DAB \\
\hline Ortiz et al. (2007) & ILD & Murine MSCs & Bone marrow & $\downarrow \mid \mathrm{L}-1$ and $\mathrm{TNF}-\alpha$ & $5 \times 10^{5}$ cells-intrajug-ODAB \\
\hline $\begin{array}{l}\text { Huang et al. } \\
(2015)\end{array}$ & Pulmonary fibrosis & Rat MSCs & Bone marrow & $\downarrow$ oxidative stress and collagen deposition & $2,5 \times 10^{6}$ cells-tail vein -0-7DAB \\
\hline Lee et al. (2014) & ALI & Murine MSCs & Bone marrow & $\begin{array}{l}\downarrow \text { TGF- } \beta, \downarrow I L-1 \beta, \downarrow \text { VEGF }, \downarrow \text { TNF- } \alpha, \downarrow I L-6, \\
\downarrow \text { NOS }\end{array}$ & $1 \times 10^{7}$-tail vein-4DAB \\
\hline Ono et al. (2015) & IPF & Human MSCs & Bone marrow & $\begin{array}{l}\downarrow \text { endoplasmic reticulum stress, } \downarrow \text { oxidative } \\
\text { stress, } \downarrow \text { TGF- } \beta 1\end{array}$ & $5 \times 10^{5}$ cells-tail vein-0-1DAB \\
\hline Lan et al. (2015) & IPF & Murine MSCs & Bone marrow & $\downarrow$ inflammation, $\uparrow$ lung function & $5 \times 10^{5}$ cells-intratrach-0-3DAB \\
\hline $\begin{array}{l}\text { Cahill et al. } \\
(2016)\end{array}$ & IPF & Murine MSCs & Bone marrow & $\downarrow I L-1 \beta, \downarrow$ apoptosis, $\uparrow$ HGF & $5 \times 10^{4}$ cells-tail vein-6h-9DAB \\
\hline $\begin{array}{l}\text { Kotani T et al. } \\
(2017)\end{array}$ & $\mathbb{I P}$ & Murine ADSCs & Adipose tissue & $\downarrow$ inflammation, $\downarrow$ fibrosis & $2,5 \times 10^{4}$ cells-tail vein-0-7DAB \\
\hline Lee et al. (2014) & IPF & Human ADSCs & Adipose tissue & $\begin{array}{l}\downarrow \text { fibrosis, } \downarrow \text { apoptosis, } \downarrow \text { TGF- } \beta, \downarrow \text { epithelial } \\
\text { cell hyperplasia }\end{array}$ & $3 \times 10^{5}$ cells-intraper. 0-DAB \\
\hline $\begin{array}{l}\text { Tashiro et al. } \\
\text { (2015) }\end{array}$ & IPF & Murine ADSCs & Adipose tissue & $\begin{array}{l}\downarrow \text { oxidative stress, } \downarrow \text { fibrosis, } \downarrow \text { apoptosis, } \downarrow \\
\text { TGF- } \beta, \downarrow \text { MMP-2 }\end{array}$ & $5 \times 10^{5}$ cells-tail vein-1DAB \\
\hline Yu et al. (2015) & IPF & Murine MSCs & Bone marrow & $\begin{array}{l}\uparrow \text { lung injury repair } \downarrow \text { fibrosis, } \downarrow \text { INF } \gamma \downarrow \text { MMP- } 1 \\
\downarrow \text { TGF- } \beta, \downarrow \text { MMP-9 }\end{array}$ & $2.5 \times 10^{6}$ cells-tail vein-1,3,6DAB \\
\hline $\begin{array}{l}\text { Rubio et al. } \\
\text { (2017) }\end{array}$ & IPF & Murine MSCs & Adipose tissue & $\begin{array}{l}\downarrow l \text { lung and skin fibrosis, } \downarrow \text { miR- } \\
199-3 p \uparrow C A V-1\end{array}$ & $5 \times 10^{5}$ cells-tail vein-1DAB \\
\hline
\end{tabular}

further investigated the mechanism and timing of MSCs administration in bleomycin-induced pulmonary fibrosis. They demonstrated that BM-MSCs administration at day 3 and day 6 decreased lung fibrosis and inflammation down-regulating MMP9, TIMP-1, INF- $\gamma$ and TGF- $\beta$ to the same extent as after day 1 of bleomycin treatment. Thus, they stated that delayed BM-MSCs administration for up to 6 days after bleomycin treatment might be effective but did not look at longer intervals (Yu et al., 2015). Ni et al. demonstrated that in a humanized mouse model of BLM-induced lung fibrosis, human BM-MSCs administered at day 2 after bleomycin injection could prevent the progression of pulmonary fibrosis suppressing bleomycin-induced human T-cell infiltration and pro-inflammatory cytokine production targeting the $\mathrm{PD}-1 /$ programmed death-ligand 1 pathway. However, BM-MSCs administration at day 7 after BLM injection did not improve lung function nor reverse established fibrosis. The authors concluded that human BMMSCs administration displayed anti-fibrotic effects only in the early phase of BLM induced lung damage, namely the inflammatory phase ( $\mathrm{Ni}$ et al., 2018). Taken together, these studies demonstrate that while MSCs are effective in mitigating acute lung inflammation and preventing development of lung fibrosis, they do not reverse established fibrosis. As IPF is usually diagnosed only after extensive fibrotic changes are present, this raises questions as to whether MSCs administration will be beneficial in IPF. However, in a recent study from Zakaria et al. in albino rats BM-MSCs systemically administered 28 days after bleomycininduction of lung damage; resulted in reversion of established fibrosis, restored lung architecture, and improved lung functions (Zakaria et al., 2021). The mechanisms by which these effects occurred need further study and may open up better understanding that will support use of systemically administered MSCs in IPF.

To date, the immunomodulatory effects of systemic or intratracheal administration of allogeneic and also xenogeneic MSCs on both the innate and adaptive immune response have been intensively explored (Masterson et al., 2019). In contrast, less is known about the interaction of lung resident MSCs with the immune system and role of LR-MSCs in pathogenesis or repair from lung injuries.

Finally, along with the beneficial role of exogenous MSCs administration, there are studies using gene therapy to improve the MSCs potency for the resolution of lung injury in different animal models. To this purpose, overexpressing of MSCs with 
HGF (HGF-MSCs) which is a growth factor with antiinflammatory, antiapoptotic, and reparative properties, have also been tested in acute lung injury models. To this purpose, MSC-based hepatocyte growth factor (HGF) has been used as gene therapy for RILI (radiation-induced lung injury). Mice receiving single dose radiation with $20 \mathrm{~Gy}$ of $\gamma$ rays locally to the lung and-HGF-modified MSCs (MSCs-HGF) revealed improved histopathological and biochemical markers of lung injury. MSCs-HGF reduced secretion and expression of proinflammatory cytokines, such as TNF- $\alpha$, interferon- $\gamma$, interleukin (IL)-6, and intercellular adhesion molecule-1, increasing the expression level of anti-inflammatory cytokine IL-10 and decreasing the expression levels of profibrotic factors TGF- $\beta$, Collal and Col3al culminating in the reduction of lung fibrosis progression (Wang et al., 2013) In another study from Chen and collaborators, rat bone marrowderived MSCs transfected to express HGF increased MSCs viability, and inhibit the proinflammatory phenotype of MSCs in the inflammatory condition. In the rat model of ischemia/ reperfusion I/R-induced lung injury, MSCs-HGF administration enhanced $\mathrm{PaO}_{2}$ level and ameliorate lung pathological injury, compared with MSCs treatment (Chen et al., 2017).

\section{PRE-CLINICAL STUDIES INVOLVING EXTRACELLULAR VESICLES DERIVED MESENCHYMAL STROMAL/STEM CELLS IN LUNG FIBROSIS}

Given their ability to reduce inflammation and their action on myofibroblast activity, MSC-derived secretome and EVs have been increasingly investigated for development of new therapeutic strategies for lung fibrosis (Worthington and Hagood, 2020). In bleomycin-induced fibrosis in immunocompetent CD1 mice, lung spheroid cell-secretome (LSC-Sec) and exosomes (LSC-Exo) derived from human LSCs generated from whole lung samples were administered by inhalation to treat fibrosis progression. Starting at day 10 mice received daily nebulized inhalations for seven consecutive days with a dose of $10 \mathrm{mg}$ of secretome protein per $\mathrm{kg}$ of body weight or $10 \times 10^{9}$ exosomes particles per $\mathrm{kg}$ of body weight or an equal volume of PBS (Dinh et al., 2020). The results demonstrated that both LSC-Sec and LSC-Exo treatments could attenuate and resolve bleomycin-induced lung fibrosis, restoring normal alveolar structure and decreasing both collagen accumulation and myofibroblast proliferation. Indeed, they showed that LSC-Exo reproduced part of the regenerative potency of the full secretome, while LSC-Exo overcame MSC-Exo in resolving pulmonary fibrosis and healthy lung function (Dinh et al., 2020).

Shentu and co-workers demonstrated in in vitro studies that MSC-derived EVs can play an antifibrotic role demonstrating down-regulation of TGF- $\beta$ induced differentiation of isolated lung fibroblasts into myofibroblast, interaction with resident myofibroblasts through Thy 1 , and delivery of miRNAs targeting profibrotic genes. To this purpose, MSC-EVs bearing
miR-630, a powerful suppressor of pro-fibrotic genes in lung fibroblasts, was used to reduce a-SMA expression in lung fibroblasts (Shentu et al., 2017; Fujita et al., 2018). Mansouri and collaborators demonstrated that human BM-MSCs-derived exosomes prevented and reverted experimental pulmonary fibrosis along with the modulation of monocyte phenotypes in bleomycin mice model (Mansouri et al., 2019). In particular, they initially evaluated the preventive effect of a single dose of human BM-derived MSCs (Mex) administered concurrently with endotracheal administration of bleomycin in 14-week-old mice on day 0 . The results demonstrated that at day 7 , Mex administration significantly reduced the bleomycin-induced pulmonary fibrosis and restored collagen content to levels similar to their bleomycin untreated-counterparts. In parallel studies, Mex administration at either day 7 or on day 21 decreased collagen content compared to control animals, although the administration after 21 days was not able to decrease the Aschroft score (Mansouri et al., 2019). Since it is known that in lung diseases LR-MSCs can migrate from their tissue niche toward the alveolar space and can be recovered from the BAL fluid, LR-MSCs EVs have been isolated from BAL fluid (Sinclair et al., 2016; Shah et al., 2019). To this purpose, MartinMedina et al.; isolated EVs from BALF collected from mice 14 days after intratracheal bleomycin, IPF patients, non IPF ILD patients, non ILD patients where BALF was performed for diagnostic evaluation (unclear cough) and ILD was excluded, and healthy volunteers as controls. The EVs were then characterized by transmission electron microscopy, nanoparticle tracking analysis, and Western blotting which demonstrated increased number of exosomes, according to their size distribution, in BALF from experimental lung fibrosis (bleomycin mouse model) and from patients with IPF compared to patients with non- ILD/non-IPF ILD. Notably, EVs from IPF BALF stimulated Wnt5A-mediated proliferation of primary human lung fibroblasts in in vitro studies (MartinMedina et al., 2018).

\section{CLINICAL STUDIES INVOLVING MESENCHYMAL STROMAL/STEM CELLS IN LUNG FIBROSIS}

Clinical studies of MSCs administration in IPF patients to date have mainly consisted of small phase I safety investigations. MSCs are known to express major histocompatibility complex I (MHC I) and lack MHC II expression, a mechanism that allows them to escape immune host reaction. However, when MSCs are systemically infused, the high level of procoagulant tissue factor (TF) expressed might trigger the instant blood-mediated inflammatory reaction (IBMIR) with potential lethal consequences for patients. Thus, it has become crucial to find strategies aiming at modulating MSCs hemocompatibility in order to increase safety and efficacy of intravascular MSCs therapies (Moll et al., 2019). Focusing on IPF, the first phase I trial performed by Tzouvelekis et al.; showed safety of MSCs 
application. This was a phase Ib, non-randomized, open label clinical trial to study the safety of three endobronchial infusions of autologous adipose derived stromal cells (ADSCs)-stromal vascular fraction (SVF) in patients with IPF $(n=14)$ of mild to moderate disease severity. They showed an acceptable safety profile with attributable serious short and long-term adverse events in all patients. However, there was no apparent suggestion of efficacy and the study was not designed to detect efficacy (Tzouvelekis et al., 2013). Another phase I safety clinical trial (AETHER) utilized a single intravenous infusion of allogeneic BM-MSCs in nine patients with mild to moderate IPF. No serious adverse events as death, pulmonary embolism, stroke and hospitalization for worsening dyspnea were observed through 60 weeks although two deaths occurred because of progression of IPF. Secondary exploratory end points demonstrated a decline in \% predicted FVC and DLCO below the defined thresholds for IPF disease progression, however, this non-controlled trial was not designed to evaluate changes in lung function (Glassberg et al., 2017). However, as the pre-clinical data, to date, more strongly suggests a potential beneficial role of MSCs administration in reducing inflammation and preventing development of fibrosis rather than reversing established fibrosis, it would be informative to explore the effect of MSCs administration in an acute exacerbation of IPF for instance following a respiratory virus infection. However, to the best of our knowledge there are not as yet pre-clinical studies based on the induction of experimental respiratory virus infection in mice with bleomycin-induced fibrosis treated with administered MSCs.

\section{CONCLUSION AND FUTURE PERSPECTIVE}

There are multiple potential roles of MSCs in lung fibrosis. On one hand, given the lessons learned from preclinical studies, further strategies can be developed in which exogenously administered MSCs might contribute to prevent disease progression or might even revert established lung fibrosis, suppressing inflammation and supporting alveolar repair. This will involve further clarification on the route and timing of MSCs administration, source and age of MSCs administered and other factors that have thus far given rise to the heterogeneous results of available preclinical data. On the other hand, lung resident MSCs might contribute to IPF pathogenesis and progression as they might differentiate into

\section{REFERENCES}

Adams, T. S., Schupp, J. C., Poli, S., Ayaub, E. A., Neumark, N., Ahangari, F., et al. (2019). Single Cell RNA-Seq Reveals Ectopic and Aberrant Lung Resident Cell Populations in Idiopathic Pulmonary Fibrosis. bioRxiv. doi:10.1101/759902

Agha, E. E., Herold, S., Alam, D. A. L., Quantius, J., Mackenzie, B., Carraro, G., et al. (2014). Fgf10 -positive Cells Represent a Progenitor Cell Population during Lung Development and Postnatally, 296-306. doi:10.1242/dev.099747 myofibroblast following lung damage. Moreover, whereas the role of LR-MSCs in lung fibrosis pathology is still being elucidated, it remains presently unknown whether healthy LR-MSCs could potentially restore/rescue this function. Since the microenvironment to which MSCs are exposed seems to regulate function and to affect further cellular development, it is arguable that healthy LR-MSCs might have a therapeutical effect in terms of lung regeneration. Thus, further work on characterizing MSCs from different sources, including LRMSCs, in terms of function, phenotype and secretome will contribute to a greater understanding of the mechanism of disease in the aim of developing specialized and targeted approaches to treat lung fibrosis. Furthermore, besides the characterization of different MSCs sources, the gene therapy based on a deeper knowledge of molecular scenario of MSCs after their administration, would improve their potency and potentiate their effect to treat specific disease.

\section{AUTHOR CONTRIBUTIONS}

AS and RT equally contributed to the conception, design, writing, and editing of the manuscript and they should be considered both first author. IH and AM (4th author) wrote and critically edited the manuscript. AM (5th author), GB, IC, DA and FG reviewed the literature, designed the review, wrote the manuscript, and produced figures. LM, AM (11th author), SC, RF, LT, CN and IM wrote the manuscript and produced figures. DW, MD and EC critically reviewed and edited the manuscript. All the authors read and approved the final version of the manuscript.

\section{FUNDING}

Manuscript has been produced within the research program at Experimental Pneumology, University of Modena and Reggio Emilia (www.experimentalpneumology.unimore.it) with Dipartimenti Eccellenti Fundings (Miur 2017).

\section{ACKNOWLEDGMENTS}

We thank FIMARP (Federazione Italiana MAlattie Rare del Polmone), Modena Golf Country Club, and AMMI (Associazione Mogli di Medici Italiani) for their support to our research.

Agha, E. E. L., Moiseenko, A., Kheirollahi, V., De Langhe, S., Crnkovic, S., Kwapiszewska, G., et al. (2017). Two-Way Conversion between Lipogenic and Myogenic Fibroblastic Phenotypes Marks the Progression and Resolution of Lung Fibrosis. Cell Stem Cell 20 (2), 261-273.e3. doi:10.1016/ j.stem.2016.10.004

Aguilar, S., Chris, J. S., Katrina, M., Emma, N., Gordon, S., Geoff, L., et al. (2009). Bone Marrow Stem Cells Expressing Keratinocyte Growth Factor via an Inducible Lentivirus Protects against Bleomycin-Induced Pulmonary Fibrosis. PLoS ONE 4 (11), e8013. doi:10.1371/ journal.pone.0008013 
Alam, D. A. L., El Agha, E., Sakurai, R., Kheirollahi, V., Moiseenko, A., Danopoulos, S., et al. (2015). Evidence for the Involvement of Fibroblast Growth Factor 10 in Lipofibroblast Formation during Embryonic Lung Development. NIH 142, 4139-4150. doi:10.1242/dev.109173

Alcayaga-miranda, F., González, P. L., Lopez-verrilli, A., Aguila-díaz, C., Contreras, L., and Maroun Khoury., S. D. (2016). Prostate Tumor-Induced Angiogenesis Is Blocked by Exosomes Derived from Menstrual Stem Cells through the Inhibition of Reactive Oxygen. species 7 (28), 44462-44477. doi:10.18632/ oncotarget.9852

Alder, J. K., Stanley, S. E., Wagner, C. L., and Hamilton, M. (2015). Exome Sequencing Identifies Mutant TINF2 in a Family with Pulmonary Fibrosis. CHEST 147 (5), 1361-1368. doi:10.1378/chest.14-1947

Allen, J. T., and Spiteri, M. A. (2002). Growth Factors in Idiopathic Pulmonary Fibrosis: Relative Roles. Respir. Res. 3 (1), 13. doi:10.1186/rr162

Allen, R. J., Guillen-Guio, B., Oldham, J. M., Ma, S. F., Amy, D., Paynton, M. L., et al. (2020). Genome-wide Association Study of Susceptibility to Idiopathic Pulmonary Fibrosis. Am. J. Respir. Crit. Care Med. 201 (5), 564-574. doi:10.1164/rccm.201905-1017OC

Allen, R. J., Porte, J., Braybrooke, R., Flores, C., Fingerlin, T. E., Oldham, J. M., et al. (2017). Genetic Variants Associated with Susceptibility to Idiopathic Pulmonary Fibrosis in People of European Ancestry: a Genome-wide Association Study. Lancet Respir. Med. 5 (11), 869-880. doi:10.1016/S22132600(17)30387-9

Andrianifahanana, M., Wilkes, M. C., Gupta, S. K., Rahimi, R. A., Repellin, C. E., Edens, M., et al. (2013). Profibrotic TGF $\beta$ Responses Require the Cooperative Action of PDGF and ErbB Receptor Tyrosine Kinases. FASEB J. 27 (11), 4444-4454. doi:10.1096/fj.12-224907

Angeles, L. (2015). TISSUE -SPECIFIC STEM CELLS Progenitors of Secondary Crest Myofibroblasts Are Developmentally Committed in Early Lung. Stem Cells 33 (3), 999-1012. doi:10.1002/stem.1911

Antoniou, K. M., Karagiannis, K., Tsitoura, E., Bibaki, E., Lasithiotaki, I., Proklou, A., et al. (2018). Clinical Applications of Mesenchymal Stem Cells in Chronic Lung Diseases (Review). Biomed. Rep. 8 (4), 314-318. doi:10.3892/br.2018.1067

Antunes, M. A., Laffey, J. G., Pelosi, P., and Patricia, R. M. (2014). Mesenchymal Stem Cells Trials for Pulmonary Disease. J. Cel Biochem 115 (6), 1023-1032. doi:10.1002/jcb. 24783

Atashi, F., Modarressi, A., and Pepper, M. S. (2015). The Role of Reactive Oxygen Species in Mesenchymal Stem Cell Adipogenic and Osteogenic Differentiation: a Review. Stem Cell Dev 24 (10), 1150-1163. doi:10.1089/scd.2014.0484

Barczyk, M., Matthias, S., and Sabrina, M. (2015). Stem Cell-Based Therapy in Idiopathic Pulmonary Fibrosis. Stem Cel Rev. Rep. 11 (4), 598-620. doi:10.1007/ s12015-015-9587-7

Barron, L., Gharib, S. A., and Duffield, J. S. (2016). Lung Pericytes and Resident Fibroblasts: Busy Multitaskers. Am. J. Pathol. 186 (10), 2519-2531. doi:10.1016/ j.ajpath.2016.07.004

Bartis, D., Louise, E. C., Vijay, K. D., Lee, B., Fisher, A. J., Croft, A. P., et al. (2016). Role of CD248 as a Potential Severity Marker in Idiopathic Pulmonary Fibrosis. BMC Pulm. Med. 16 (1), 1-10. doi:10.1186/s12890-016-0211-7

Beer, L., Mildner, M., and Jan Ankersmit, H. (2017). Cell Secretome Based Drug Substances in Regenerative Medicine: when Regulatory Affairs Meet Basic Science. Ann. Transl Med. 5 (7), 5-7. doi:10.21037/atm.2017.03.50

Beers, M. F., and Morrisey, E. E. (2011). Science in Medicine the Three R's of Lung Health and Disease: Repair, Remodeling, and Regeneration. J. Clin. Invest. 121 (6), 2065-2073. doi:10.1172/JCI45961.respiratory

Behnke, J., Kremer, S., Shahzad, T., Chao, C., Böttcher-Friebertshäuser, E., Morty, R. E., et al. (2020). MSC Based Therapies-New Perspectives for the Injured Lung. J. Clin. Med. 9 (3), 682. doi:10.3390/jcm9030682

Bellaye, P. S., and Kolb, M. (2015). Why Do Patients Get Idiopathic Pulmonary Fibrosis? Current Concepts in the Pathogenesis of Pulmonary Fibrosis. BMC Med. 13 (1), 1-3. doi:10.1186/s12916-015-0412-6

Betensley, A., Sharif, R., and Karamichos, D. (2016). A Systematic Review of the Role of Dysfunctional Wound Healing in the Pathogenesis and Treatment of Idiopathic Pulmonary Fibrosis. J. Clin. Med. 6 (1), 2. doi:10.3390/jcm6010002

Bitterman, P. (2018). Fibroblast-Matrix Cross-Talk in Idiopathic Pulmonary Fibrosis: Cross-Links at the Crossroads. Am. J. Respir. Cel Mol. Biol. 58 (5), 547-548. doi:10.1165/rcmb.2017-0402ED
Blokland, K. E. C., Waters, D. W., Schuliga, M., Read, J., Pouwels, S. D., Grainge, C. L., et al. (2020). Senescence of Ipf Lung Fibroblasts Disrupt Alveolar Epithelial Cell Proliferation and Promote Migration in Wound Healing. Pharmaceutics 12 (4). doi:10.3390/pharmaceutics 12040389

Bochaton-Piallat, L., Gabbiani, G., and Hinz, B. (2016). The Myofibroblast in Wound Healing and Fibrosis: Answered and Unanswered Questions. F1000Research 5 (0), 1-8. doi:10.12688/f1000research.8190.1

Bolanos, A. L., Mendoza Milla, C., Lira, J. C., Ramírez, R., Checa, M., Barrera, L., et al. (2012). Role of Sonic Hedgehog in Idiopathic Pulmonary Fibrosis. Am. J. Physiol. - Lung Cell Mol. Physiol. 303 (11), 978-990. doi:10.1152/ ajplung.00184.2012

Bonser, L., and Erle, D. (2017). Airway Mucus and Asthma: The Role of MUC5AC and MUC5B. J. Clin. Med. 6 (12), 112. doi:10.3390/jcm6120112

Burgess, J. K., and Irene, H. H. (2019). Stem Cell-Based Therapy for Lung Disease. Springer. doi:10.1007/978-3-030-29403-8

Cahill, E. F., Kennelly, H., Carty, F., Mahon, B. P., and English, K. (2016). Hepatocyte Growth Factor Is Required for Mesenchymal Stromal Cell Protection against Bleomycin-Induced Pulmonary Fibrosis. Stem Cell Transl Med 5 (10), 1307-1318. doi:10.5966/sctm.2015-0337

Cao, H., Chen, X., Hou, J., Wang, C., Zou, X., Shen, Y., et al. (2019). The Shh/Gli Signaling cascade Regulates Myofibroblastic Activation of Lung-Resident Mesenchymal Stem Cells via the Modulation of Wnt10a Expression during Pulmonary Fibrogenesis. Lab. Invest. 100 (3), 363-377. doi:10.1038/s41374019-0316-8

Cao, H., Wang, C., Chen, X., Hou, J., Zou, X., Shen, Y., et al. (2018). Inhibition of Wnt/ $\beta$-Catenin Signaling Suppresses Myofibroblast Differentiation of Lung Resident Mesenchymal Stem Cells and Pulmonary Fibrosis. Scientific Rep. 8 (1), 1-14. doi:10.1038/s41598-018-28968-9

Cao, S. S., and Kaufman, R. J. (2012). Unfolded Protein Response. Curr. Biol. 22 (16), R622-R626. PMID: 22917505. doi:10.1016/j.cub.2012.07.004

Cargnoni, A., Gibelli, L., Tosini, A., Signoroni, P. B., Nassuato, C., Arienti, D., et al. (2009). Transplantation of Allogeneic and Xenogeneic Placenta-Derived Cells Reduces Bleomycin-Induced Lung Fibrosis. Cel Transplant. 18 (4), 405-422. doi:10.3727/096368909788809857

Cerri, S., Monari, M., Guerrieri, A., Donatelli, P., Bassi, I., Garuti, M., et al. (2019). Real-life Comparison of Pirfenidone and Nintedanib in Patients with Idiopathic Pulmonary Fibrosis: A 24-month Assessment. Respir. Med. 159 (10), 105803. doi:10.1016/j.rmed.2019.105803

Chanda, D., Otoupalova, E., Smith, S. R., Volckaert, T., Stijn, P. D., and Victor, J. T. (2019). Developmental Pathways in the Pathogenesis of Lung Fibrosis. Mol. Aspects Med. 65 (7), 56-69. doi:10.1016/j.mam.2018.08.004

Chen, S., Chen, X., Wu, X., Wei, S., Han, W., Lin, J., et al. (2017). Hepatocyte Growth Factor-Modified Mesenchymal Stem Cells Improve Ischemia/ reperfusion-Induced Acute Lung Injury in Rats. Gene Ther. 24 (1), 3-11. Epub 2016 Aug 24: PMID: 27556817. doi:10.1038/gt.2016.64

Chen, X., Shi, C., Cao, H., Chen, L., Hou, J., Zou, X., et al. (2018). The Hedgehog and Wnt/ $\beta$-Catenin System Machinery Mediate Myofibroblast Differentiation of LR-MSCs in Pulmonary. Cel Death Dis. 9 (6), 639. doi:10.1038/s41419-018-0692-9

Chilosi, M., Poletti, V., Zamò, A., Lestani, M., Montagna, L., Piccoli, P., et al. (2003). Aberrant Wnt/beta-Catenin Pathway Activation in Idiopathic Pulmonary Fibrosis. Am. J. Pathol. 162 (5), 1495-1502. PMID: 12707032; PMCID: PMC1851206. doi:10.1016/s0002-9440(10)64282-4

Chong, S., Sato, S., Kolb, M., and Gauldie, J. (2019). Fibrocytes and Fibroblasts-Where Are We Now. Int. J. Biochem. Cel Biol. 116 (August), 105595. doi:10.1016/j.biocel.2019.105595

Cigna, N., Elika, F. M., Brayer, S., Marchal-Somme, J., Wémeau-Stervinou, L., Fabre, A., et al. (2012). The Hedgehog System Machinery Controls Transforming Growth Factor- $\beta$-dependent Myofibroblastic Differentiation in Humans: Involvement in Idiopathic Pulmonary Fibrosis. Am. J. Pathol. 181 (6), 2126-2137. doi:10.1016/j.ajpath.2012.08.019

Collard, H. R., Ryerson, C. J., Corte, T. J., Jenkins, G., Kondoh, Y., Lederer, D. J., et al. (2016). Acute Exacerbation of Idiopathic Pulmonary Fibrosis an International Working Group Report. Am. J. Respir. Crit. Care Med. 194 (3), 265-275. doi:10.1164/rccm.201604-0801CI

Cruz, F. F., and Patricia, R. M. R. (2020). The Potential of Mesenchymal Stem Cell Therapy for Chronic Lung Disease. Expert Rev. Respir. Med. 14 (1), 31-39. doi:10.1080/17476348.2020.1679628 
Dabrowska, S., Anna, A., and Janowski, M. (2021). Immunomodulatory and Regenerative Effects of Mesenchymal Stem Cells and Extracellular Vesicles: Therapeutic Outlook for in Fl Ammatory and Degenerative Diseases. Front. Immunol. 11 (2), 591065. doi:10.3389/fimmu.2020.591065

David, M. H., and Cory, M. H. (2017). Heterogeneity of Fibroblasts and Myofibroblasts in Pulmonary Fibrosis. Physiol. Behav. 176 (3), 139-148. doi:10.1007/s40139-017-0134-x

Dinh, P., Uyen, C. D., Paudel, D., Brochu, H., Kristen, D. P., Gracieux, M. C., et al. (2020). Inhalation of Lung Spheroid Cell Secretome and Exosomes Promotes Lung Repair in Pulmonary Fibrosis. Nat. Commun. 11 (1). doi:10.1038/s41467-020-14344-7

Dominici, M., Le Blanc, K., Mueller, I., Slaper-Cortenbach, I., Marini, F. C., Krause, D. S., et al. (2006). Minimal Criteria for Defining Multipotent Mesenchymal Stromal Cells. The International Society for Cellular Therapy Position Statement. Cytotherapy 8 (4), 315-317. doi:10.1080/14653240600855905

Doubková, M., Radová, L., Michaela, P., Trizuljak, J., Karol, P., Svobodová, K., et al. (2019). A Novel Germline Mutation of the SFTPA1 Gene in Familial Interstitial Pneumonia, 4-9. doi:10.1038/s41439-019-0044-z

Dressen, A., Abbas, A. R., Cabanski, C., Reeder, J., Ramalingam, T. R., Neighbors, M., et al. (2018). Analysis of Protein-Altering Variants in Telomerase Genes and Their Association with MUC5B Common Variant Status in Patients with Idiopathic Pulmonary Fibrosis: a Candidate Gene Sequencing Study. Lancet Respir. Med. 6 (8), 603-614. doi:10.1016/S2213-2600(18)30135-8

El Agha, E., Moiseenko, A., Kheirollahi, V., De Langhe, S., Crnkovic, S., and Kwapiszewska, G. (2017). Two-Way Conversion Between Lipogenic and Myogenic Fibroblastic Phenotypes Marks the Progression and Resolution of Lung Fibrosis. Cell Stem Cell 20 (4), 571. doi:10.1016/j.stem.2017.03.011. Erratum for: Cell Stem Cell. 2017 Feb 2;20(2):261-273.e3. PMID: 28388434

Enes, R. S., Ahrman, E., Palani, A., Hallgren, O., Bjermer, L., Malmström, A., et al. (2017). Quantitative Proteomic Characterization of Lung-MSC and Bone Marrow-MSC Using DIA-Mass Spectrometry. Springer, 1-12. doi:10.1038/ s41598-017-09127-y

Ferguson, S. W., and Nguyen, J. (2016). Exosomes as Therapeutics: The Implications of Molecular Composition and Exosomal Heterogeneity. J. Controlled Release 228, 179-190. doi:10.1016/j.jconrel.2016.02.037

Fernandez, I. E., and Oliver, E. (2012). New Cellular and Molecular Mechanisms of Lung Injury and Fi Brosis in Idiopathic Pulmonary Fi Brosis. The Lancet 380 (9842), 680-688. doi:10.1016/S0140-6736(12)61144-1

Fingerlin, T. E., Murphy, E., Zhang, W., Peljto, A. L., Brown, K. K., Steele, M. P., et al. (2013). Genome-wide Association Study Identifies Multiple Susceptibility Loci for Pulmonary Fibrosis. Nat. Genet. 45 (6), 613-620. doi:10.1038/ng.2609

Fomby, P., Cherlin, A. J., Hadjizadeh, A., Doillon, C. J., Sueblinvong, V., Weiss, D. J., et al. (2010). Stem Cells and Cell Therapies in Lung Biology and Diseases: Conference Report. Ann. Am. Thorac. Soc. 12 (3), 181-204. doi:10.1002/term

Fujita, Y., Kadota, T., Araya, J., Ochiya, T., and Kuwano, K. (2018). Clinical Application of Mesenchymal Stem Cell-Derived Extracellular Vesicle-Based Therapeutics for Inflammatory Lung Diseases. J. Clin. Med. 7 (10), 355. doi: $10.3390 /$ jcm7100355

Gao, F., Chiu, S. M., Motan, D. A. L., Zhang, Z., Chen, L., Ji, H. L., et al. (2016). Mesenchymal Stem Cells and Immunomodulation: Current Status and Future Prospects. Cel Death Dis. 7 (1). doi:10.1038/cddis.2015.327

Gazdic, M., Volarevic, V., Arsenijevic, N., and Stojkovic, M. (2015). Mesenchymal Stem Cells: A Friend or Foe in Immune-Mediated Diseases. Stem Cel Rev. Rep. 11 (2), 280-287. doi:10.1007/s12015-014-9583-3

Geissler, S., Textor, M., Schmidt-Bleek, K., Klein, O., Thiele, M., Ellinghaus, A., et al. (2013). In Serum Veritas-In Serum Sanitas? Cell Non-autonomous Aging Compromises Differentiation and Survival of Mesenchymal Stromal Cells via the Oxidative Stress Pathway. Cell Death Dis 4 (12), e970, 2013. PMID: 24357801; PMCID: PMC3877568. doi:10.1038/cddis.2013.501

Gharibi, B., and Hughes, F. J. (2012). Effects of Medium Supplements on Proliferation, Differentiation Potential, and In Vitro Expansion of Mesenchymal Stem Cells. Stem Cell Transl Med 1 (11), 771-782. Epub 2012 Oct 23. PMID: 23197689; PMCID: PMC3659663. doi:10.5966/sctm.2010-0031

Glaspole, I., Glassberg, M. K., Gorina, E., Hopkins, P. M., David, K., Teherani, A., et al. (2014). A Phase 3 Trial of Pirfenidone in Patients with Idiopathic Pulmonary Fibrosis. N. Engl. J. Med. 2014, 2083-2092. doi:10.1056/NEJMoa1402582

Glassberg, M. K., Julia, M., Rebecca, L. T., Emmanuelle, S. S., Gustavo, A. R., Darcy, D., et al. (2017). Allogeneic Human Mesenchymal Stem Cells in Patients with
Idiopathic Pulmonary Fibrosis via Intravenous Delivery (AETHER): A Phase I Safety Clinical Trial. Chest 151 (5), 971-981. doi:10.1016/j.chest.2016.10.061

Gokey, J. J., Sridharan, A., Xu, Y., Green, J., Carraro, G., Stripp, B. R., et al. (2018). Active Epithelial Hippo Signaling in Idiopathic Pulmonary Fibrosis. JCI insight 3 (6), e98738. doi:10.1172/jci.insight. 98738

Golchin, A., Seyedjafari, E., and Ardeshirylajimi, E. (2020). Mesenchymal Stem Cell Therapy for COVID-19: Present or Future. Stem Cel Rev. Rep. 16 (3), 427-433. doi:10.1007/s12015-020-09973-w

Green, J., Endale, M., Auer, H., and Anne Karina, T. P. (2016). Diversity of Interstitial Lung Fibroblasts Is Regulated by Platelet-Derived Growth Factor Receptor a Kinase Activity. Am. J. Respir. Cel Mol. Biol. 54 (4), 532-545. doi:10.1165/rcmb.2015-0095OC

Gu, Z., Cao, X., Jiang, J., Li, L., Da, Z., Liu, H., et al. (2012). Upregulation of p16INK4A Promotes Cellular Senescence of Bone Marrow-Derived Mesenchymal Stem Cells from Systemic Lupus Erythematosus Patients. Cell Signal 24 (12), 2307-2314. Epub 2012 Jul 20. PMID: 22820504. doi:10.1016/ j.cellsig.2012.07.012

Guenther, A., Krauss, E., Tello, S., Wagner, J., Paul, B., Kuhn, S., et al. (2018). The European IPF Registry (eurIPFreg): Baseline Characteristics and Survival of Patients With Idiopathic Pulmonary Fibrosis. Respir Res. 28 (1), 141. doi:10.1186/s12931-018-0845-5

Guescini, M., Genedani, S., Stocchi, V., and Agnati, L. F. (2010). Astrocytes and Glioblastoma Cells Release Exosomes Carrying mtDNA. J. Neural Transm. 117 (1), 1-4. doi:10.1007/s00702-009-0288-8

Hancock, L. A., Hennessy, C. E., Solomon, G. M., Dobrinskikh, E., Estrella, A., Hara, N., et al. (2018). Muc5b Overexpression Causes Mucociliary Dysfunction and Enhances Lung Fibrosis in Mice. Nat. Commun. 9 (1), 1-10. doi:10.1038/ s41467-018-07768-9

Harrell, C., Fellabaum, C., Jovicic, N., Djonov, V., Arsenijevic, N., and Volarevic, V. (2019). Molecular Mechanisms Responsible for Therapeutic Potential of Mesenchymal Stem Cell-Derived Secretome. Cells 8 (5), 467. doi:10.3390/ cells 8050467

Hasaneen, N. A., Cao, J., Pulkoski-gross, A., Zucker, S., and Hussein, D. F. (2016). Extracellular Matrix Metalloproteinase Inducer (EMMPRIN) Promotes Lung Fibroblast Proliferation, Survival and Differentiation to Myofibroblasts. Respir. Res. 17, 1-14. doi:10.1186/s12931-016-0334-7

Henderson, W., Chi, E. Y., Ye, X., Nguyen, C., Tien, Y. T., Zhou, B., et al. (2010). Inhibition of Wnt/ $\beta$-catenin/CREB Binding Protein (CBP) Signaling Reverses Pulmonary Fi Brosis, 14309-14314. doi:10.1073/pnas.1001520107

Herrera, I., Cisneros, J., Maldonado, M., Ramírez, R., Ortiz-Quintero, B., Elena, A., et al. (2013). Matrix Metalloproteinase (MMP)-1 Induces Lung Alveolar Epithelial Cell Migration and Proliferation, Protects from Apoptosis, and Represses Mitochondrial Oxygen Consumption. J. Biol. Chem. 288 (36), 25964-25975. doi:10.1074/jbc.M113.459784

Hinz, B. (2012). Mechanical Aspects of Lung Fibrosis: A Spotlight on the Myofibroblast. Proc. Am. Thorac. Soc. 9 (3), 137-147. doi:10.1513/ pats.201202-017AW

Hinz, B., Phan, S. H., Thannickal, V. J., and Galli, A. (2007). Marie Luce BochatonPiallat, Giulio Gabbiani. 2007. The Myofibroblast: One Function, Multiple Origins. Am. J. Pathol. 170 (6), 1807-1816. doi:10.2353/ajpath.2007.070112

Hoffman, A. M., Paxson, J. A., Mazan, M. R., Davis, A. M., Tyagi, S., Murthy, S., et al. (2011). Lung-derived Mesenchymal Stromal Cell post-transplantation Survival, Persistence, Paracrine Expression, and Repair of Elastase-Injured Lung. Stem Cell Dev 20 (10), 1779-1792. Epub 2011 Jul 6. PMID: 21585237; PMCID: PMC3182034. doi:10.1089/scd.2011.0105

Horowitz, J. C., and Thannickal, V. J. (2019). Mechanisms for the Resolution of Organ Fibrosis. Physiology 34 (1), 43-55. doi:10.1152/physiol.00033.2018

Hu, H. H., Chen, D. Q., Wang, Y. N., Feng, Y. L., Cao, G., Vaziri, N. D., et al. (2018). New Insights into TGF- $\beta /$ Smad Signaling in Tissue Fibrosis. Chem. Biol. Interact 292, 76-83. Epub 2018 Jul 11. PMID: 30017632. doi:10.1016/j.cbi.2018.07.008

Huang, K., Kang, X., Wang, X., Wu, S., Xiao, J., Li, Z., et al. (2015). Conversion of Bone Marrow Mesenchymal Stem Cells into Type II Alveolar Epithelial Cells Reduces Pulmonary Fibrosis by Decreasing Oxidative Stress in Rats. Mol. Med. Rep. 11, 1685-1692. doi:10.3892/mmr.2014.2981

Huleihel, L., Sellares, J., Cardenes, N., Álvarez, D., Faner, R., Sakamoto, K., et al. (2017). Modified Mesenchymal Stem Cells Using miRNA Transduction Alter Lung Injury in a Bleomycin Model. Am. J. Physiol. - Lung Cel. Mol. Physiol. 313, L92-L103. doi:10.1152/ajplung.00323.2016 
Hung, C., Linn, G., Chow, Y., Kobayashi, A., Mittelsteadt, K., Altemeier, W. A., et al. (2013). Role of Lung Pericytes and Resident Fibroblasts in the Pathogenesis of Pulmonary Fibrosis. Am. J. Respir. Crit. Care Med. 188 (7), 820-830. PMID: 23924232; PMCID: PMC3826269. doi:10.1164/rccm.201212$22970 \mathrm{C}$

Iwayama, T., Steele, C., Yao, L., Dozmorov, M. G., Karamichos, D., Wren, J. D., et al. (2015). PDGFRa Signaling Drives Adipose Tissue Fibrosis by Targeting Progenitor Cell Plasticity. Genes Dev. 29 (11), 1106-1119. doi:10.1101/ gad.260554.115

Jaffar, J., Griffiths, K., Oveissi, S., Duan, M., Foley, M., Glaspole, I., et al. (2020). CXCR4+cells Are Increased in Lung Tissue of Patients with Idiopathic Pulmonary Fibrosis. Respir. Res. 21 (1), 1-16. doi:10.1186/s12931-02001467-0

Jarvinen, L., Badri, L., Scott, W., Standiford, T. J., Toews, G. B., David, J., et al. (2021). Lung Resident Mesenchymal Stem Cells Isolated from Human Lung Allografts Inhibit T Cell Proliferation via a Soluble Mediator. J. Immunol. 181 (6), 4389-4396. doi:10.4049/jimmunol.181.6.4389

Jenkins, R. G., Moore, B. B., Chambers, R. C., Oliver, E., Konigshoff, M., Kolb, M., et al. (2017). An Official American Thoracic Society Workshop Report: Use of Animal Models for the Preclinical Assessment of Potential Therapies for Pulmonary Fibrosis. Am. J. Respir. Cel Mol. Biol. 56 (5), 667-679. doi:10.1165/rcmb.2017-0096ST

Jessica Germaine, S., Teresa Pay, M., Lara Compte, C., Olid, M., Bermudo, G., Portillo, K., et al. (2020). Mapping IPF Helps Identify Geographic Regions at Higher Risk for Disease Development and Potential Triggers. Respirology 26, 1-8. doi:10.1111/resp.13973

Jiang, Y., Mishima, H., Sakai, S., Liu, Y. K., Ohyabu, Y., and Uemura, T. (2008). Gene Expression Analysis of Major Lineage-Defining Factors in Human Bone Marrow Cells: Effect of Aging, Gender, and Age-Related Disorders. J. Orthop. Res. 26 (7), 910-917. PMID: 18302252. doi:10.1002/jor.20623

Jun, D., Garat, C., West, J., Thorn, N., Chow, K., Cleaver, T., et al. (2011). The Pathology of Bleomycin-Induced Fibrosis Is Associated with Loss of Resident Lung Mesenchymal Stem Cells that Regulate Effector T-Cell Proliferation. Stem Cells 29 (4), 725-735. doi:10.1002/stem.604

Jo, H. E., Glaspole, I., Grainge, C., Goh, N., Hopkins, P. M., Moodley, Y., Reynolds, P. N., et al. (2017). Baseline Characteristics of Idiopathic Pulmonary Fibrosis: Analysis From the Australian Idiopathic Pulmonary Fibrosis Registry. Eur. Respir J. 49 (2), 1601592. doi:10.1183/13993003.01592-2016. Erratum in: Eur Respir J. 2017 Mar 29;49(3): PMID: 28232409

Karki, S., Surolia, R., David Hock, T., Guroji, P., Zolak, J. S., Ryan, D., et al. (2014). Wilms' Tumor 1 (Wt1) Regulates Pleural Mesothelial Cell Plasticity and Transition into Myofibroblasts in Idiopathic Pulmonary Fibrosis. FASEB J. 28 (3), 1122-1131. doi:10.1096/fj.13-236828

Kheirollahi, V., Wasnick, R. M., Biasin, V., Vazquez-Armendariz, A. I., Chu, X., Moiseenko, A., et al. (2019). Metformin Induces Lipogenic Differentiation in Myofibroblasts to Reverse Lung Fibrosis. Nat. Commun. 10 (1), 2987, 2019. PMID: 31278260; PMCID: PMC6611870. doi:10.1038/s41467-019-10839-0

Kim, K. K., Kugler, M. C., Paul, J., Robillard, L., Galvez, M. G., Alexis, M., et al. (2006). Alveolar Epithelial Cell Mesenchymal Transition Develops In Vivo during Pulmonary Fibrosis and Is Regulated by the Extracellular Matrix. Proc. Natl. Acad. Sci. United States America 103 (35), 13180-13185. doi:10.1073/ pnas.0605669103

Kim, S. Y., Lee, J. H., Kim, H. J., Park, M. K., Huh, J. W., Ro, J. Y., et al. (2012). Mesenchymal Stem Cell-Conditioned media Recovers Lung Fibroblasts from Cigarette Smoke-Induced Damage. Am. J. Physiol. - Lung Cell Mol. Physiol. 302 (9), L891-L908. doi:10.1152/ajplung.00288.2011

King, T. E., Pardo, A., and Selman, M. (2011). Idiopathic Pulmonary Fibrosis. The Lancet 378 (9807), 1949-1961. doi:10.1016/S0140-6736(11)60052-4

Kirkland, J. L., and Tchkonia, T. (2017). Cellular Senescence: A Translational Perspective. EBioMedicine 21, 21-28. doi:10.1016/j.ebiom.2017.04.013

Kis, K., Liu, X., James, S., and Hagood, S. (2011). Myofibroblast Differentiation and Survival in Fibrotic Disease. Expert Rev. Mol. Med. 13 (2), e27. doi:10.1017/ S1462399411001967

Kleaveland, K. R., Miranda, V., Yang, J., Agarwal, M., Rippe, R. A., Bethany, B., et al. (2014). Fibrocytes Are Not an Essential Source of Type I Collagen during Lung Fibrosis. J. Immunol. 193 (10), 5229-5239. doi:10.4049/jimmunol.1400753
Klein, D. (2020). Lung Multipotent Stem Cells of Mesenchymal Nature: Cellular Basis. Clin. relevance implications Stem Cel. Ther. 5, 1-38. doi:10.1089/ ars.2020.8190

Kotani, T., Masutani, R., Suzuka, T., Oda, K., Makino, S., and Li, M. (2017). Anti-Inflammatory and Anti-Fibrotic Effects of Intravenous AdiposeDerived Stem Cell Transplantation in a Mouse Model of BleomycinInduced Interstitial Pneumonia. Sci. Rep. 7 (1), 14608, 2017. Erratum in: Sci Rep. 2018 Jan 8;8(1):454. Erratum in: Sci Rep. 2018 Mar 6;8(1):4222. PMID: 29097816.

Kramann, R., Schneider, R. K., Dirocco, D. P., Machado, F., Fleig, S., Bondzie, P. A., et al. (2015). Perivascular Gli1+ Progenitors Are Key Contributors to InjuryInduced Organ Fibrosis. Cell Stem Cell 16 (1), 51-66. doi:10.1016/ j.stem.2014.11.004

Kropski, J. A., Daphne, B. M., Cheryl, M., Vasiliy, V. P., Choi, L., Joyce, E. J., et al. (2014). A Novel Dyskerin (DKC1) Mutation Is Associated with Familial Interstitial Pneumonia. CHEST 146 (1), e1-7. doi:10.1378/ chest.13-2224

Kropski, J. A., Jason, M. P., Donald, F. Z., Peter, F. C., Markin, C., Garnett, E. T., et al. (2015). Extensive Phenotyping of Individuals at Risk for Familial Interstitial Pneumonia Reveals Clues to the Pathogenesis of Interstitial Lung Disease. Am. J. Respir. Crit. Care Med. 191 (4), 417-426. doi:10.1164/ rccm.201406-1162OC

Kruk, D. M. L. W., Wisman, M., de Bruin, H. G., Lodewijk, M. E., Danique, J., Borghuis, T., et al. (2021). Abnormalities in Reparative Function of LungDerived Mesenchymal Stromal Cells in Emphysema. Am. J. Physiology-Lung Cell Mol. Physiol. marzo 320. doi:10.1152/ajplung.00147.2020

Lan, Y. W., Choo, K. B., Chen, C. M., Hung, T. H., Chen, Y. Bin., Hsieh, C. H., et al. (2015). Hypoxia-preconditioned Mesenchymal Stem Cells Attenuate Bleomycin-Induced Pulmonary Fibrosis. Stem Cel Res. Ther. 6, 1-17. doi:10.1186/s13287-015-0081-6

Larsson, H., Le Blanc, K., Eriksson, L., Bjermer, L., and Scheding, S. (2016). MSC from Fetal and Adult Lungs Possess Lung-specific Properties Compared to Bone Marrow-Derived. Nature Publishing Group, 1-10. doi:10.1038/srep29160

Lederer, D. J., and Martinez, F. J. (2018). Idiopathic Pulmonary Fibrosis. New Engl. J. Med. 378 (19), 1811-1823. doi:10.1056/NEJMra1705751

Lee, J. K., Park, S., Jung, B., Jeon, Y., Lee, Y., Kim, K., et al. (2013). Exosomes Derived from Mesenchymal Stem Cells Suppress Angiogenesis by DownRegulating VEGF Expression in Breast Cancer. Cells 8 (12). doi:10.1371/ journal.pone.0084256

Lee, S., Lee, E., Lee, S., Kim, J., Shim, J., Shin, C., et al. (2014). The Effect of Adipose Stem Cell Therapy on Pulmonary Fibrosis Induced by Repetitive Intratracheal Bleomycin in Mice. Exp. Lung Res. 40 (3), 117-125. doi:10.3109/ 01902148.2014 .881930

Lehmann, M., Hu, Q., Hu, Y., Hafner, K., Costa, R., van den Berg, A., et al. (2020). Chronic Wnt/ $\beta$-Catenin Signaling Induces Cellular Senescence in Lung Epithelial Cells. Cell Signal. 70 (October), 109588. doi:10.1016/ j.cellsig.2020.109588

Lehmann, M., Korfei, M., Mutze, K., Klee, S., Skronska-wasek, W., Alsafadi, H. N., et al. (2017). Senolytic Drugs Target Alveolar Epithelial Cell Function and Attenuate Experimental. Eur. Respir. J. 50 (2), 1602367. doi:10.1183/ 13993003.02367-2016

Ley, B., Collard, H. R., and King, T. E. (2011). Clinical Course and Prediction of Survival in Idiopathic Pulmonary Fibrosis. Am. J. Respir. Crit. Care Med. 183 (4), 431-440. doi:10.1164/rccm.201006-0894CI

Ley, B., Newton, C. A., Arnould, I., Elicker, B. M., Henry, T. S., Vittinghoff, E., et al. (2017). The MUC5B Promoter Polymorphism and Telomere Length in Patients with Chronic Hypersensitivity Pneumonitis: an Observational Cohort-Control Study. Lancet Respir. Med. 5 (8), 639-647. doi:10.1016/ S2213-2600(17)30216-3

Li, F., Han, F., Li, H., Zhang, J., Qiao, X., Shi, J., et al. (2017a). Human Placental Mesenchymal Stem Cells of Fetal Origins-Alleviated Inflammation and Fibrosis by Attenuating MyD88 Signaling in Bleomycin-Induced Pulmonary Fibrosis Mice. Mol. Immunol. 90, 11-21. doi:10.1016/j.molimm.2017.06.032

Li, Y., Wu, Q., Wang, Y., Li, L., Bu, H., and Bao, J. (2017b). Senescence of Mesenchymal Stem Cells (Review). Int. J. Mol. Med. 39 (4), 775-782. Epub 2017 Mar 9. PMID: 28290609. doi:10.3892/ijmm.2017.2912 
Liu, J., Ding, Y., Liu, Z., and Liang, X. (2020). Senescence in Mesenchymal Stem Cells: Functional Alterations, Molecular Mechanisms, and Rejuvenation Strategies. Front Cel Dev Biol 8, 258, 2020 . PMID: 3. doi:10.3389/ fcell.2020.00258

López-Otín, C., Blasco, M. A., Partridge, L., Serrano, M., and Kroemer, G. (2013). The Hallmarks of Aging. Cell. 153 (6), 1194-1217. PMID: 23746838; PMCID: PMC3836174. doi:10.1016/j.cell.2013.05.039

Lou, G., Chen, Z., Zheng, M., and Liu, E. Y. (2017). Mesenchymal Stem CellDerived Exosomes as a New Therapeutic Strategy for Liver Diseases. Exp. Mol. Med. 49 (6), e346. doi:10.1038/emm.2017.63

Maguire, Greg. (2013). Stem Cell Therapy without Cells. Communicative Integr. Biol. 6 (6), e2663. doi:10.4161/cib.26631

Mansouri, N., Willis, G. R., Fernandez-Gonzalez, A., Reis, M., Nassiri, S., Alex Mitsialis, S., et al. (2019). Mesenchymal Stromal Cell Exosomes Prevent and Revert Experimental Pulmonary Fibrosis through Modulation of Monocyte Phenotypes. JCI Insight 4 (21), 1-17. doi:10.1172/ jci.insight. 128060

Marchioni, A., Tonelli, R., Rossi, G., Spagnolo, P., Luppi, F., Cerri, S., et al. (2020). Ventilatory Support and Mechanical Properties of the Fibrotic Lung Acting as a "squishy ball". Ann. Intensive Care 10 (1), 13, 2020 . PMID: 32020548; PMCID: PMC7000609. doi:10.1186/s13613-020-0632-6

Marriott, S., Baskir, R. S., Gaskill, C., Menon, S., Carrier, E. J., Williams, J., et al. (2014). ABCG2pos Lung Mesenchymal Stem Cells Are a Novel Pericyte Subpopulation that Contributes to Fibrotic Remodeling. Am. J. Physiol. - Cel Physiol. 307 (8), C684-C698. doi:10.1152/ajpcell.00114.2014

Martin, A., Jahn, A., Rio, C., Iglesias, A., Mercader, J., Montes, A., et al. (2020). Characterizing Lung Resident Mesenchymal Stem Cells in Idiopathic Pulmonary Fibrosis. Eur. Respir. J. 56 (Suppl. 64). doi:10.1183/ 13993003.congress-2020.457

Martin-Medina, A., Lehmann, M., Olivier, B., Hermann, S., Baarsma, H. A., Wagner, D. E., et al. (2018). Increased Extracellular Vesicles Mediate Wnt5A Signaling in Idiopathic Pulmonary Fibrosis. Am. J. Respir. Crit. Care Med. 198 (12), 1527-1538. doi:10.1164/rccm.201708-1580OC

Massagué, J. (2014). TGFbeta Signalling in Context. Nat. Rev. Mol. Cel Biol 13 (10), 616-630. doi:10.1038/nrm3434.TGF

Masterson, C. H., Curley, G. F., and Laffey, J. G. (2019). Modulating the Distribution and Fate of Exogenously Delivered. MSCs enhance Ther. potential: knowns unknowns 7 (Suppl. 1), 1-21. doi:10.1186/s40635-0190235-4

Mastrolia, I., Foppiani, E. M., Alba, M., Candini, O., Samarelli, A. V., Grisendi, G., et al. (2019). Challenges in Clinical Development of Mesenchymal Stromal/ Stem Cells: Concise Review. Stem Cell Translational Med. 8 (11), 1135-1148. doi:10.1002/sctm.19-0044

Meng, F., Xu, R., Wang, S., Xu, Z., Zhang, C., Li, Y., et al. (2020). Human Umbilical Cord-Derived Mesenchymal Stem Cell Therapy in Patients with COVID-19: a Phase 1 Clinical Trial. Signal. Transduction Targeted Ther. 5 (1). doi:10.1038/ s41392-020-00286-5

Meng, X. M., Nikolic-Paterson, D. J., and Lan, H. Y. (2016). TGF- $\beta$ : The Master Regulator of Fibrosis. Nat. Rev. Nephrol. 12 (6), 325-338. doi:10.1038/ nrneph.2016.48

Michalski, J. E., and Schwartz, D. A. (2020). Genetic Risk Factors for Idiopathic Pulmonary Fibrosis: Insights into Immunopathogenesis. J. Inflamm. Res. 13, 1305-1318. doi:10.2147/JIR.S280958

Moeller, A., Kjetil, A., Warburton, D., Gauldie, J., and Kolb, M. (2008). The Bleomycin Animal Model: A Useful Tool to Investigate Treatment Options for Idiopathic Pulmonary Fibrosis? Int. J. Biochem. Cel Biol. 40 (3), 362-382. doi:10.1016/j.biocel.2007.08.011

Moll, G., James, A. A., Julian, K-M., Karen, B., Olle, R., Hans, D. V., et al. (2019). Intravascular Mesenchymal Stromal/Stem Cell Therapy Product Diversification: Time for New Clinical Guidelines. Trends Mol. Med. 25 (2), 149-163. doi:10.1016/j.molmed.2018.12.006

Moodley, Y., Atienza, D., Manuelpillai, U., Samuel, C. S., Tchongue, J., Ilancheran, S., et al. (2009). Human Umbilical Cord Mesenchymal Stem Cells Reduce Fibrosis of Bleomycin-Induced Lung Injury. Am. J. Pathol. 175 (1), 303-313. doi:10.2353/ajpath.2009.080629

Moodley, Y., Vaghjiani, V., Chan, J., Baltic, S., Ryan, M., Tchongue, J., et al. (2013). Anti-Inflammatory Effects of Adult Stem Cells in Sustained Lung
Injury: A Comparative Study. PLoS One 8, e69299. doi:10.1371/ journal.pone.0069299

Moore, B. B., Jill, E. K., Victor, J. T., Cooke, K., Moore, T. A., Hogaboam, C., et al. (2005). CCR2-mediated Recruitment of Fibrocytes to the Alveolar Space after Fibrotic Injury. Am. J. Pathol. 166 (3), 675-684. doi:10.1016/S0002-9440(10) 62289-4

Mora, A. L., Rojas, M., Pardo, A., and Selman, M. (2017). Emerging Therapies for Idiopathic Pulmonary Fibrosis, a Progressive Age-Related Disease. Nat. Rev. Drug Discov. 16 (11), 755-772. doi:10.1038/nrd.2017.170

Ni, K., Liu, M., Zheng, J., Wen, L., Chen, Q., Zheng, X., et al. (2018). PD-1/PD-L1 Pathway Mediates the Alleviation of Pulmonary Fibrosis by Human Mesenchymal Stem Cells in Humanized Mice. Am. J. Respir. Cel Mol. Biol. 58 (6), 684-695. doi:10.1165/rcmb.2017-0326OC

Noble, P. W., Albera, C., Williamson, Z. B., Ulrich, C., Glassberg, M. K., Kardatzke, D., et al. (2011). Pirfenidone in Patients with Idiopathic Pulmonary Fi Brosis (CAPACITY): Two Randomised Trials. The Lancet 377 (9779), 1760-1769. doi:10.1016/S0140-6736(11)60405-4

Noguchi, S., Saito, A., and Nagase, T. (2018). YAP/TAZ Signaling as a Molecular Link between Fibrosis and Cancer. Int. J. Mol. Sci. 19 (11). doi:10.3390/ ijms19113674

Nureki, S. I., Tomer, Y., Venosa, A., Katzen, J., Russo, A. J., Jamil, S., et al. (2018). Expression of Mutant Sftpc in Murine Alveolar Epithelia Drives Spontaneous Lung Fibrosis. J. Clin. Invest. 128 (9), 4008-4024. doi:10.1172/JCI99287

Ono, M., Ohkouchi, S., Kanehira, M., Tode, N., Kobayashi, M., Ebina, M., et al. (2015). Mesenchymal Stem Cells Correct Inappropriate EpithelialMesenchyme Relation in Pulmonary Fibrosis Using Stanniocalcin-1. Mol. Ther. 23, 549-560. doi:10.1038/mt.2014.217

Ortiz, L. A., Gambelli, F., McBride, C., Gaupp, D., Baddoo, M., Kaminski, N., et al. (2003). Mesenchymal Stem Cell Engraftment in Lung Is Enhanced in Response to Bleomycin Exposure and Ameliorates its Fibrotic Effects. Proc. Natl. Acad. Sci. United States America 100 (14), 8407-8411. doi:10.1073/pnas.1432929100

Ortiz, L. A., DuTreil, M., Fattman, C., Pandey, A. C., Torres, G., Go, K., et al. (2007). Interleukin 1 Receptor Antagonist Mediates the Antiinflammatory and Antifibrotic Effect of Mesenchymal Stem Cells during Lung Injury. Proc. Natl. Acad. Sci. U. S. A. 104, 11002-11007. doi:10.1073/pnas.0704421104

Pardo, A., Gibson, K., Cisneros, J., Richards, T. J., Yang, Y., Becerril, C., et al. (2005). Up-regulation and Profibrotic Role of Osteopontin in Human Idiopathic Pulmonary Fibrosis. PLoS Med. 2 (9), 0891-0903. doi:10.1371/ journal.pmed.0020251

Pardo, A., and Moisés Selman, E. (2021). The Interplay of the Genetic Architecture, Aging, and Environmental Factors in the Pathogenesis of Idiopathic Pulmonary Fibrosis. Am. J. Respir. Cel Mol. Biol. 64 (2), 163-172. doi:10.1165/rcmb.20200373ps

Phan, Sem. H. (2002). The Myofibroblast in Pulmonary Fibrosis. Chest 122 (6 Suppl. L), 286S-289S. doi:10.1378/chest.122.6_suppl.286S

Phan, T., Paliogiannis, P., Nasrallah, G. K., Giordo, R., Hussein Eid, A., Giuseppe Fois, A., et al. (2020). Emerging Cellular and Molecular Determinants of Idiopathic Pulmonary Fibrosis. Cell Mol. Life Sci. 78, 2031-2057. doi:10.1007/s00018-020-03693-7

Phillips, R. J., Burdick, M. D., Hong, K., Lutz, M. A., Murray, L. A., Ying Xue, Y., et al. (2004). Circulating Fibrocytes Traffic to the Lungs in Response to CXCL12 and Mediate Fibrosis. J. Clin. Invest. 114 (3), 438-446. doi:10.1172/JCI200420997

Plantier, L., Crestani, B., Wert, S. E., Dehoux, M., Zweytick, B., Guenther, A., et al. (2011). Ectopic Respiratory Epithelial Cell Differentiation in Bronchiolised Distal Airspaces in Idiopathic Pulmonary Fibrosis. Thorax 66 (8), 651-657. Epub 2011 Mar 21: PMID: 21422041. doi:10.1136/thx.2010.151555

Powers, E. T., Morimoto, R. I., Dillin, A., Kelly, J. W., and Balch, W. E. (2009). Biological and Chemical Approaches to Diseases of Proteostasis Deficiency. Annu. Rev. Biochem. 78, 959-991. PMID: 19298183. doi:10.1146/ annurev.biochem.052308.114844

Qiu, T., Tian, Y., Gao, Y., Ma, M., Li, H., Liu, X., et al. (2019). PTEN Loss Regulates Alveolar Epithelial Cell Senescence in Pulmonary Fibrosis Depending. Akt activation 11 (18), 7492-7509. doi:10.18632/aging.102262 on

Raghu, G., Harold, C., Egan, J. J., Martinez, F. J., Behr, J., Brown, K. K., et al. (2011). An Official ATS/ERS/JRS/ALAT Statement: Idiopathic Pulmonary Fibrosis: Evidence-Based Guidelines for Diagnosis and Management. Am. J. Respir. Crit. Care Med. 183 (6), 788-824. doi:10.1164/rccm.2009-040GL.Ricciardi 
Ricciardi, M., Giorgio, M., Francesco, B., Giulio, B., Luciano, P., and Nwabo, K. A. H. (2012). Comparison of Epithelial Differentiation and Immune Regulatory Properties of Mesenchymal Stromal Cells Derived from Human Lung and Bone Marrow. PLoS One 7 (5), 1-10. doi:10.1371/journal.pone.0035639

Richeldi, L., Collard, H. R., and Jones, M. G. (2017). Idiopathic Pulmonary Fibrosis. The Lancet 389 (10082), 1941-1952. doi:10.1016/S0140-6736(17)30866-8

Rock, J. R., Christina, E., Michael, J., Xue, Y., Harris, J. R., Liang, J., et al. (2011). "Multiple Stromal Populations Contribute to Pulmonary Fibrosis without Evidence for Epithelial to Mesenchymal Transition," in Proceedings of the National Academy of Sciences of the United States of America (US: NIH). doi:10.1073/pnas.1117988108

Rolandsson, S., Andersson Sjöland, S., Brune, J. C., Li, H., Kassem, M., Mertens, F., et al. (2014). Primary Mesenchymal Stem Cells in Human Transplanted Lungs Are CD90/CD105 Perivascularly Located Tissue-Resident Cells. BMJ Open Respir. Res. 1 (1), 1-12. doi:10.1136/bmjresp-2014-000027

Roy, M. G., Livraghi-butrico, S., Fletcher, A. A., Mcelwee, M. M., Scott, E. E., Ryan, M. B., et al. (2013). Muc5b Is Required for Airway Defence. Nature 505 (7483), 412-416. doi:10.1038/nature12807

Rubio, G. A., Elliot, S. J., Wikramanayake, T., Xia, X., Pereira-simon, S., Seth, R., et al. (2017). Mesenchymal Stromal Cells Prevent Bleomycin-Induced Lung and Skin Fibrosis in Aged Mice and Restore Wound Healing †. J. Cel Physiol 233 (8), 5503-5512. doi:10.1002/jcp.26418

Ryu, J. H., Teng, M., Daniels, C. E., Hartman, T. E., Yi, E. S., Utz, J. P., et al. (2014). Idiopathic Pulmonary Fibrosis: Evolving Concepts. Mayo Clinic Proc. 89 (8), 1130-1142. doi:10.1016/j.mayocp.2014.03.016

Schröder, M., and Kaufman, R. J. (2005). The Mammalian Unfolded Protein Response. Annu. Rev. Biochem. 74, 739-789. PMID: 15952902. doi:10.1146/ annurev.biochem.73.011303.074134

Scotton, C. J., and Chambers, R. C. (2007). Molecular Targets in Pulmonary Fibrosis: The Myofibroblast in Focus. Chest 132 (4), 1311-1321. doi:10.1378/ chest.06-2568

Seibold, M. A., Smith, R. W., Urbanek, C., Steve, D. G., Cosgrove, G. P., Brown, K. K., et al. (2013). The Idiopathic Pulmonary Fibrosis Honeycomb Cyst Contains A Mucocilary Pseudostratified Epithelium. PLoS ONE 8 (3). doi:10.1371/ journal.pone.0058658

Selman, M., and Pardo, A. (2020). The Leading Role of Epithelial Cells in the Pathogenesis of Idiopathic Pulmonary Fibrosis. Cell Signal. 66 (November 2019), 109482. doi:10.1016/j.cellsig.2019.109482

Sgalla, G., Cocconcelli, E., Tonelli, R., and Richeldi, L. (2016). Novel Drug Targets for Idiopathic Pulmonary Fibrosis. Expert Rev. Respir. Med. 10 (4), 393-405. doi:10.1586/17476348.2016.1152186

Shah, T. G., Predescu, D., and Predescu, S. (2019). Mesenchymal Stem Cellsderived Extracellular Vesicles in Acute Respiratory Distress Syndrome: a Review of Current Literature and Potential Future Treatment Options. Clin. Translational Med. 8 (1), 4-9. doi:10.1186/s40169-019-0242-9

Shentu, T. P., Huang, T. S., Cernelc-Kohan, M., Chan, J., Wong, S. S., Espinoza, C. R., et al. (2017). Thy-1 Dependent Uptake of Mesenchymal Stem Cell-Derived Extracellular Vesicles Blocks Myofibroblastic Differentiation. Scientific Rep. 7 (1), 1-11. doi:10.1038/s41598-017-18288-9

Shi, J., Li, F., Luo, M., Wei, J., and Liu, X. (2017). Distinct Roles of Wnt/B-Catenin Signaling in the Pathogenesis of Chronic Obstructive Pulmonary Disease and Idiopathic Pulmonary Fibrosis. Mediators Inflamm. 2017, 3520581. doi:10.1155/2017/3520581

Sinclair, K. A., Yerkovich, S. T., Chen, T., McQualter, J. L., Hopkins, P. M. A., Wells, C. A., et al. (2016). Mesenchymal Stromal Cells Are Readily Recoverable from Lung Tissue, but Not the Alveolar Space, in Healthy Humans. Stem Cells 34 (10), 2548-2558. doi:10.1002/stem.2419

Stanley, S. E., Gable, D. L., Wagner, C. L., Carlile, T. M., Vidya Sagar, H., Joshua, D. P., et al. (2016). Loss-of-function Mutations in the RNA Biogenesis Factor NAF1 Predispose to Pulmonary Fibrosis - Emphysema. Sci. Transl Med. 8 (351), 1-10. doi:10.1126/scitranslmed.aaf7837

Steele, M. P., Brown, K. K., James, E. L., Tasha E Fingerlin, D., Zhang, W., Adler, K. B., et al. (2011). A Common. N. Engl. J. Med. 364 (16), 1503-1512.

Steens, J., Klar, L., Hansel, C., Alexis, S., Hager, T., Jendrossek, V., et al. (2021). The Vascular Nature of Lung-Resident Mesenchymal Stem Cells. Stem Cell Translational Med. 10 (1), 128-143. doi:10.1002/sctm.20-0191

Stuart, B. D., Choi, J., Zaidi, S., Xing, C., Holohan, B., Chen, R., et al. (2015). Exome Sequencing Links Mutations in PARN and RTEL1 with Familial Pulmonary
Fibrosis and Telomere Shortening. Nat. Genet. 47 (5), 512-517. doi:10.1038/ ng. 3278

Summers, M. E., Richmond, B. W., Kropski, J. A., Majka, S. A., Bastarache, J. A., Hatzopoulos, A. K., et al. (2021). Balanced Wnt/Dickkopf-1 Signaling by Mesenchymal Vascular Progenitor Cells in the Microvascular Niche Maintains Distal Lung Structure and Function. Am. J. Physiol. Cel Physiol 320 (1), C119-C131. Epub 2020 Oct 21. PMID: 33085496; PMCID: PMC7846975. doi:10.1152/ajpcell.00277.2020

Sveiven, S. N., and Nordgren, T. M. (2020). Lung-resident Mesenchymal Stromal Cells Are Tissue-specific Regulators of Lung Homeostasis. Am. J. Physiol. - Lung Cell Mol. Physiol. 319 (2), L197-L210. doi:10.1152/ AJPLUNG.00049.2020

Sun, T., Huang, Z., Zhang, H., Posner, C., Posner, G., and Ramalingam, T. R. (2019). TAZ is Required for Lung Alveolar Epithelial Cell Differentiation After Injury. JCI Insight 5, e128674. doi:10.1172/jci.insight.128674

Takezaki, A., Tsukumo, S., Setoguchi, Y., Ledford, J. G., Goto, H., Hosomichi, K., et al. (2019). A Homozygous SFTPA1 Mutation Drives Necroptosis of Type II Alveolar Epithelial Cells in Patients with Idiopathic Pulmonary Fibrosis. J. Exp. Med. 216 (12), 2724-2735. doi:10.1084/jem.20182351

Tashiro, J., Elliot, S. J., Gerth, D. J., Xia, X., Pereira-Simon, S., Choi, R., et al. (2015). Therapeutic Benefits of Young, but Not Old, Adipose-Derived Mesenchymal Stem Cells in a Chronic Mouse Model of Bleomycin-Induced Pulmonary Fibrosis. Transl. Res. 166, 554-567. doi:10.1016/j.trsl.2015.09.004

Tong, L., Zhou, J., Rong, L., Seeley, E. J., Pan, J., Zhu, X., et al. (2016). Fibroblast Growth Factor-10 (FGF-10) Mobilizes Lung-Resident Mesenchymal Stem Cells and Protects against Acute Lung Injury. Scientific Rep. 6 (September), 1-12. doi:10.1038/srep21642

Tzouvelekis, A., Paspaliaris, V., George, K., Ntolios, P., Bouros, E., Oikonomou, A., et al. (2013). A Prospective, Non-randomized, No Placebo-Controlled, Phase Ib Clinical Trial to Study the Safety of the Adipose Derived Stromal Cells-Stromal Vascular Fraction in Idiopathic Pulmonary Fibrosis. J. Transl Med. 11, 171. doi:10.1186/1479-5876-11-171

Uccelli, A., Moretta, L., and Pistoia, V. (2008). Mesenchymal Stem Cells in Health and Disease. Nat. Rev. Immunol. 8 (9), 726-736. doi:10.1038/nri2395

Ulke, H. M., Mutze, K., Lehmann, M., Wagner, D. E., Heinzelmann, K., Günther, A., et al. (2019). The Oncogene ECT2 Contributes to a Hyperplastic, Proliferative Lung Epithelial Cell Phenotype in Idiopathic Pulmonary Fibrosis. Am. J. Respir. Cel Mol. Biol. 61 (6), 713-726. doi:10.1165/ rcmb.2019-0047OC

Valadi, H., Ekström, K., Bossios, A., Sjöstrand, M., James, J., and Lee, O. (2007). Exosome-mediated Transfer of mRNAs and microRNAs Is a Novel Mechanism of Genetic Exchange between Cells. Nat. Cel Biol. 9 (6), 654-659. doi:10.1038/ncb1596

Vaughan, A. E., Brumwell, A. N., Xi, Y., Gotts, J. E., Brownfield, D. G., Treutlein, B., et al. (2015). Lineage-negative Progenitors Mobilize to Regenerate Lung Epithelium after Major Injury. Nature 517 (7536), 621-625. doi:10.1038/ nature 14112

Vaz, M., Hwang, S. Y., Kagiampakis, I., Phallen, J., Patil, A., O’Hagan, H. M., et al. (2017). Chronic Cigarette Smoke-Induced Epigenomic Changes Precede Sensitization of Bronchial Epithelial Cells to Single-step Transformation by KRAS Mutations. Cancer Cell 32 (3), 360-376.e6. doi:10.1016/ j.ccell.2017.08.006

Vishnubhatla, I., Randolph, C., Stevanato, L., Hicks, C., and Sinden, J. (2014). The Development of Stem Cell-Derived Exosomes as a Cell-free Regenerative Medicine. J. Circulating Biomarkers 3, 1-14. doi:10.5772/58597

Vizoso, F. J., Eiro, N., Cid, S., Schneider, J., and Perez-Fernandez, R. (2017). Mesenchymal Stem Cell Secretome: Toward Cell-free Therapeutic Strategies in Regenerative Medicine. Int. J. Mol. Sci. 18 (9), 1852. doi:10.3390/ijms18091852

Wang, H., Yang, Y. F., Zhao, L., Xiao, F. J., Zhang, Q. W., Wen, M. L., et al. (2013). Hepatocyte Growth Factor Gene-Modified Mesenchymal Stem Cells Reduce Radiation-Induced Lung Injury. Hum. Gene Ther. 24 (3), 343-353. Epub 2013 Mar 4. PMID: 23458413. doi:10.1089/hum.2012.177

Wang, L., Yuan, Y., Yang, X., Fan, T., Mei, B., Hou, J., et al. (2017). Platelet Derived Growth Factor Alpha (PDGFRa) Induces the Activation of Cardiac Fibroblasts by Activating C-Kit. Med. Sci. Monitor 23, 3808-3816. doi:10.12659/ MSM.906038

Wang, S., Hu, B., Ding, Z., Dang, Y., Wu, J., Li, D., et al. (2018). ATF6 Safeguards Organelle Homeostasis and Cellular Aging in Human Mesenchymal Stem Cells. 
Cell Discov 4, 2, 2018. PMID: 29423270; PMCID: PMC5798892. doi:10.1038/ s41421-017-0003-0

Weiss, D. J., and Ortiz, L. A. (2013). Cell Therapy Trials for Lung Diseases: Progress and Cautions. Am. J. Respir. Crit. Care Med. 188 (2), 123-125. doi:10.1164/ rccm.201302-0351ED

Willis, B. C., Liebler, J. M., Luby-Phelps, K., Nicholson, A. G., Crandall, E. D., Roland, M., et al. (2005). Induction of Epithelial-Mesenchymal Transition in Alveolar Epithelial Cells by Transforming Growth Factor-B1: Potential Role in Idiopathic Pulmonary Fibrosis. Am. J. Pathol. 166 (5), 1321-1332. doi:10.1016/ S0002-9440(10)62351-6

Wipff, P. J., Rifkin, D. B., Jean, J. M., and Hinz, B. (2007). Myofibroblast Contraction Activates Latent TGF-B1 from the Extracellular Matrix. J. Cel Biol. 179 (6), 1311-1323. doi:10.1083/jcb.200704042

Worthington, E. N., and Hagood, J. S. (2020). Therapeutic Use of Extracellular Vesicles for Acute and Chronic Lung Disease. Int. J. Mol. Sci. 21 (7). doi:10.3390/ijms 21072318

Wu, H., and Tang, N. (2021). Stem Cells in Pulmonary Alveolar Regeneration. Development 148 (2), dev193458. doi:10.1242/dev.193458

Xie, T., Liang, J., Liu, N., Huan, C., Zhang, Y., Liu, W., et al. (2016). Transcription Factor TBX4 Regulates Myofibroblast Accumulation and Lung Fibrosis. J. Clin. Invest. 126 (8), 3063-3079. doi:10.1172/JCI85328

Xu, C., Wang, J., Zhu, T., Shen, Y., Tang, X., Fang, L., et al. (2016a). Cross-Talking between PPAR and WNT Signaling and its Regulation in Mesenchymal Stem Cell Differentiation. Curr. Stem Cel Res Ther 11 (3), 247-254. PMID: 26201865. doi:10.2174/1574888x10666150723145707

Xu, Y., Mizuno, T., Sridharan, A., Du, Y., Guo, M., Tang, J., et al. (2016b). Singlecell RNA Sequencing Identifies Diverse Roles of Epithelial Cells in Idiopathic Pulmonary Fibrosis. JCI Insight 1 (20), e90558. doi:10.1172/jci.insight.90558

Yamada, M., Kubo, H., Kobayashi, S., Ishizawa, K., Numasaki, M., Ueda, S., et al. (2004). Bone Marrow-Derived Progenitor Cells Are Important for Lung Repair after Lipopolysaccharide-Induced Lung Injury. J. Immunol. 172 (2), 1266-1272. doi:10.4049/jimmunol.172.2.1266

Yao, C., Guan, X., Carraro, G., Parimon, T., Liu, X., Huang, G., et al. (2020). Senescence of Alveolar Type 2 Cells Drives Progressive Pulmonary Fibrosis. Am. J. Respir. Crit. Care Med. 203 (6), 707-717. doi:10.1164/rccm.202004$1274 \mathrm{oc}$

Yu, S., Liu, L-J., Lv, B., Che, C-li., Fan, D-P., Wang, L-F., et al. (2015). Inhibition of Bleomycin-Induced Pulmonary $\mathrm{Fi}$ Brosis by Bone Marrow- Derived Mesenchymal Stem Cells Might Be Mediated by Decreasing. Cell Biochem Funct 33 (6), 356-366. July. doi:10.1002/cbf.3118

Zacharias, W. J., Frank, D. B., Zepp, J. A., Morley, M. P., Alkhaleel, F., Kong, J., et al. (2018). HHS Public Access 555 (7695), 251-255. doi:10.1038/nature25786.Regeneration
Zakaria, D. M., Noha, M. Z., Samia, A. A. A., Radwa, A. M., and Rehab, A. M. (2021). Histological and Physiological Studies of the Effect of Bone MarrowDerived Mesenchymal Stem Cells on Bleomycin Induced Lung Fibrosis in Adult Albino Rats. Tissue Eng. Regenerative Med. 18 (1), 127-141. doi:10.1007/ s13770-020-00294-0

Zhang, E., Yang, Y. E., Zhang, J., Ding, G., Chen, S., Cheng, P., et al. (2019). Efficacy of Bone Marrow Mesenchymal Stem Cell Transplantation in Animal Models of Pulmonary Fibrosis after Exposure to Bleomycin : A Meta - Analysis. Exp. Ther. Med. 17 (3), 2247-2255. doi:10.3892/ etm.2019.7205

Zhang, H. Y., Gharaee-Kermani, M., Zhang, K., Karmiol, S., and Sem, H. (1996). Lung Fibroblast $\alpha$-smooth Muscle Actin Expression and Contractile Phenotype in Bleomycin-Induced Pulmonary Fibrosis. Am. J. Pathol. 148 (2), 527-537.

Zhou, B., Liu, Y., Kahn, M., David, K. A., Han, A., Wang, H., et al. (2012). Interactions between -Catenin and Transforming Growth Factor- Signaling Pathways Mediate Epithelial- Mesenchymal Transition and Are Dependent on the Element-Binding Protein ( CREB ) -binding Protein ( CBP). J. Biol. Chem. 287 (10), 7026-7038. doi:10.1074/jbc.M111.276311

Zumla, A., Fu, S. W., Chang, C., Giuseppe, I., Petrosillo, N., Agrati, C., et al. (2020). Reducing Mortality and Morbidity in Patients with Severe COVID-19 Disease by Advancing Ongoing Trials of Mesenchymal Stromal (Stem) Cell (MSC) Therapy - Achieving Global Consensus and Visibility for Cellular HostDirected Therapies. Int. J. Infect. Dis. 96, 431-439. doi:10.1016/ j.ijid.2020.05.040

Zysman, M., Baptista, B. R., Essari, L. A., Taghizadeh, S., Thibault de Ménonville, C., Giffard, C., et al. (2020). Targeting p16INK4a Promotes Lipofibroblasts and Alveolar Regeneration after Early-Life Injury. Am. J. Respir. Crit. Care Med. 202 (8), 1088-1104. PMID: 32628504. doi:10.1164/rccm.201908-1573OC

Conflict of Interest: The authors declare that the research was conducted in the absence of any commercial or financial relationships that could be construed as a potential conflict of interest.

Copyright (c) 2021 Samarelli, Tonelli, Heijink, Martin Medina, Marchioni, Bruzzi, Castaniere, Andrisani, Gozzi, Manicardi, Moretti, Cerri, Fantini, Tabbi, Nani, Mastrolia, Weiss, Dominici and Clini. This is an open-access article distributed under the terms of the Creative Commons Attribution License (CC BY). The use, distribution or reproduction in other forums is permitted, provided the original author(s) and the copyright owner(s) are credited and that the original publication in this journal is cited, in accordance with accepted academic practice. No use, distribution or reproduction is permitted which does not comply with these terms. 


\section{GLOSSARY}

IPF idiopathic pulmonary fibrosis

IIPs idiopathic interstitial pneumonias

MSCs mesenchymal stem cells

ECT2 epithelial cell transforming sequence 2

AECI alveolar epithelial cells 1

AECII alveolar epithelial cell 2

AEP alveolar epithelial progenitor

TGF- $\beta 1$ transforming growth factor beta 1

PDGF platelet-derived growth factor

VEGF vascular endothelial growth factor

FGF fibroblast growth factor

IL-1 interleukin 1

TNF- $\boldsymbol{\alpha}$ tumor necrosis factor-alpha

ERS endoplasmic reticulum stress

EMMPRIN extracellular matrix metalloproteinase inducer

CXCL12 C-X-C motif chemokine 12

CCL2 chemokine $\mathrm{C}-\mathrm{C}$ motif ligand 2

EMT epithelial mesenchymal transition

a-SMA alpha smooth-muscle actin

Shh sonic hedgehog

PTEN phosphatase and tensin homologuephosphatase and TENsin homolog

INF $\gamma$ interferon $\gamma$

PDGFRa platelet-derived growth factor receptor A

ABCA3 ATP binding cassette subfamily A member 3

DKC1 dyskerin pseudouridine synthase 1

TP53 tumor protein P53

TOLIP toll interacting protein

MUC5B mucin 5B

ECM extracellular matrix

BM bone marrow

hMSCs human mesenchymal stem cells

KGF keratinocyte growth factor

ARDS acute respiratory distress syndrome

Thy-1 or CD90 cluster of differentiation 90

BAL bronchoalveolar Lavage

SASP senescence associated secretory phenotype

uMSCs umbilical cord derived Mesenchymal Stem Cells

DLCO diffuse lung coefficient for carbon dioxide
Igfb insulin growth factor binding protein

FVC forced vital capacity

CT computed tomography

ADMSCs adipose tissue-derived mesenchymal stem cells

GEF guanine nucleotide exchange factor

CTGF connective tissue growth factor

EV extracellular vesicles

PI3K phosphatidylInositol 3-Kinase

TCF $\mathrm{T}$ cell factor

miRNA micro RNA

MVs micro vesicles

MHC I major histocompatibility complex I

HGF hepathocyte growth factor

IDO-1 indolamine 2,3-dioxygenase-1

IL-1Ra IL-1 receptor antagonist

PGE2 prostaglandin E2

PTEN phosphatase and tensin homologuephosphatase and TENsin homolog

NK natural killer cells

YAP yes-associated protein

TAZ transcriptome coactivator with PDZ-binding motif

ECs endothelial cells

GLI1 transcription factors glioma-associated homologue

MHC-1 major histocompatibility complex I

BLM bleomycin

CS cigarette smoke

SFPTA1 surfactant protein 1

CDKN1A cyclin dependent kinase inhibitor 1A

TERT telomerase reverse transcriptase

MCC mucociliary clearance

MCP1 CCL2 monocyte chemotacticprotein 1

SDF1 stromal cell-derived factor 1

TIMP tissue inhibitors of metalloproteinase

BDNF brain-derived neurotrophic factor

NGF nerve growth factor

CINC-1 cytokine-induced neutrophil chemoattractant 1

AT-MSCs adipose tissue-derived mesenchymal stem cells

COPD chronic obstructive pulmonary disease

LSC-Sec lung spheroid cell-secretome

LSC-Exo lung spheroid cell exosomes

lncRNAs long non coding RNA 